\title{
Picture the Music: Performing Arts Library Planning with Photo Elicitation
}

\author{
Nara L. Newcomer with David Lindahl and Stephanie A. Harriman
}

\begin{abstract}
Photo elicitation, a form of ethnographic journaling, provided insights into university music and dance student needs in library and campus spaces and services. In this case study, subjects took a photo for each of twenty prompts related to their daily lives as students and performing artists, then discussed their own photos in a one-hour individual interview. Researchers qualitatively analyzed the gathered data. This article reports findings related to: discovering and obtaining music and dance works, study spaces and sound levels, forces of habit and the implications for student library use, and library-related findings regarding practice rooms and classrooms.
\end{abstract}

This is an electronic version of an article published in Music Reference Services Quarterly 19, no. 1.

Newcomer, Nara L. with David Lindahl and Stephanie Harriman. "Picture the Music:

Performing Arts Library Planning with Photo Elicitation." Music Reference Services

Quarterly 19, no. 1 (March 2016): 18-62.

Music Reference Services Quarterly is available online at:

http://dx.doi.org/10.1080/10588167.2015.1130575 


\section{Introduction}

Librarians increasingly seek user feedback to shape changes and enhancements to library spaces and services. Tools such as user surveys, analysis of library statistics, and observation of predefined behavior aspects have guided many librarians towards optimally deploying ever-limited resources. Such tools provide helpful input on defined questions and are particularly valuable for addressing known problems and determining which solutions will best serve library patrons. However, by design, these tools usually stay within existing boxes, making them suboptimal for holistic examinations required to lead major innovation or uncover new and unfamiliar aspects of user needs.

At the University of Missouri-Kansas City (UMKC), an initiative to build a new arts campus presented a unique opportunity for radical change in music and dance library spaces and services. To holistically inform planning of this campus and its library, librarians harnessed ethnographic methods to research UMKC music and dance student needs, especially what students use, avoid, and wish for in library spaces and services.

\section{Background}

UMKC is a public, urban university of approximately 16,000 students on two campuses: the main campus (referred to as the Volker Campus) and the Health Sciences campus. The Conservatory of Music and Dance is currently located on the main campus and enrolls about 600 students in a full range of undergraduate, master's, doctoral, and certificate programs with areas of study including: composition, theory, and musicology; dance; instrumental studies; jazz studies; keyboard studies; music education and music therapy; and vocal studies. A growing program and campus constraints have split the conservatory's physical facilities among three buildings scattered across the main campus, with library music and dance collections housed in yet another building, the Miller Nichols Library. ${ }^{1}$ Students constantly move themselves (and often their instruments) back and forth among these buildings for classes, lessons, rehearsals, practicing, and (for some) library visits. Even utilizing such dispersed facilities, the available space is inadequate for program needs.

To address these needs, planning began for a new conservatory home: an arts campus in Kansas City's downtown "Crossroads" district, about five miles away from the current main campus and literally down the hill from the new (2011) Kauffman Center for the Performing Arts, home to Kansas City's Symphony, Ballet, and Lyric Opera. The Greater Kansas City Chamber of Commerce's "Big 5" initiative yielded an arts campus feasibility study (2012), which enabled continued planning and fundraising, including a twenty million dollar challenge grant (2013), and a pledge of real estate for a site (2014). With a site established, the university selected an architectural team to plan and create a concept design for an arts campus, and appointed campus committees and representatives to work with the architectural team.

Librarians were active planning partners throughout the Downtown Campus initiative, and a music and dance library was slated for inclusion in the new campus. New construction in a new location delivers an exciting opportunity to not merely remedy the worst existing problems, but

\footnotetext{
${ }^{1}$ The Miller Nichols Library is UMKC's largest library and the primary library for all subject areas except law, health sciences, and dentistry.
} 
to start from scratch and create ground-breaking new facilities. Research tools which begin with a pre-defined scope, while they might have reinforced (or contradicted) existing perceptions about the worst deficits, would have told too much about existing problems and too little about what students and faculty really need to do and how conservatory - and especially conservatory library - spaces could support and enhance that work. Therefore, ethnographic research methods became clear steps on the path to innovative, energetic, 21 stcentury spaces to support the conservatory community's work, learning, and performance for years to come.

Ethnographic methods are now recognized as useful and valid library research tools. This research project sought a holistic view of music and dance student needs and behaviors which the library or conservatory might facilitate or support through spaces and services. In an idealized research world, researchers might have observed subjects continuously for a week, with opportunities to encourage subjects to "think out loud" about their actions and decisions. In reality, such an approach would require too many resources and be overly invasive, leading to privacy and ethical concerns as well as validity problems because subjects under such close scrutiny would likely change their behavior. Instead, this research project utilized photo elicitation, an ethnographic method of journaling via photos. ${ }^{2}$ Photography lends concreteness to the "journal" via activities already ubiquitous in the subjects' daily lives, ${ }^{3}$ helping address the problem of people saying one thing and doing another and reducing the need to rely solely on subject memories and descriptions. In a photo elicitation study, subjects receive prompts or directions to channel their photo journaling towards the research project's foci. Subjects share their photos with the research team, then discuss the photos with one or more researchers in a follow-up interview. The interviews are usually transcribed to facilitate data analysis via various, primarily qualitative, methods.

\section{Literature Review}

Previously published research regarding performing arts library patron needs and behaviors has been most extensive in the subcategory of musician information-seeking behavior and discovery interface use. ${ }^{4}$ Other specific aspects have also been studied, such as response to presence of a staffed reference desk. ${ }^{5}$ However, only one published study has examined multiple aspects of academic music library patron behavior from an ethnographic perspective, ${ }^{6}$ and that study did not use photo elicitation methods.

In that ethnographic study, investigators Hursh and Avenarius took a mixed methods approach, beginning with an exploratory phase consisting of an original ethnographic adaptation of the

\footnotetext{
${ }^{2}$ The protocol for this research study, "UMKC Conservatory Students and Their Work" was approved by the Institutional Review Board (IRB) of the University of Missouri-Kansas City.

${ }^{3}$ Photography is ubiquitous in 21 st century United States culture, especially in the age demographic of study subjects; indeed, all subjects chose to photograph with their own device, usually a cell phone already carried constantly, rather than use a provided disposable camera.

${ }^{4}$ Kirstin Dougan, "Finding the Right Notes: An Observational Study of Score and Recording Seeking Behaviors of Music Students," The Journal of Academic Librarianship 41 (2015): 61-67. Dougan's article includes a thorough literature review of studies of music library patron information-seeking behavior.

${ }^{5}$ Nara L. Newcomer and David Hursh, "Calling All Academic Music Library Reference Desks: A Follow-Up Study." Music Reference Services Quarterly 11, no. 2 (2008): 101-129.

${ }^{6}$ David W. Hursh and Christine B. Avenarius, "What Do Patrons Really Do in Music Libraries?: An Ethnographic Approach to Improving Library Services," Music Reference Services Quarterly 16, no. 2 (2013): 84-108.
} 
classic sweeps method. In the classic sweeps method, observers visually record activity in a predetermined area (such as a library) using a predetermined checklist. In Hursh and Avenarius's study, however, observers described patrons and their activities without a predetermined checklist. Hursh and Avenarius collated and analyzed these observations, then used traditional explanatory methods (the classic sweeps methods and brief patron surveys) to confirm and expand their findings. The study resulted in a very thorough analysis of patron behavior within that branch university music library, including a preference for solitary study and a favoring of different library areas for different visit types and lengths: individual use carrels for long-term visits with more multitasking, ${ }^{7}$ and a multi-seat technology lab for shorter visits with less multitasking. However, Hursh and Avenarius did not consider patron behavior outside the physical music library space, thus ignoring use of online library resources (unless such use occurred while also in the library), as well as patron work which library spaces might support but which occurred elsewhere due to limitations of the library space, patron preferences, or any other factors. Furthermore, the study subjects were primarily undergraduate and master's level music students; dancers and doctoral students were essentially excluded because the university did not offer doctoral music degrees and dancers were not among primary users of the branch music library. ${ }^{8}$

Moving beyond the performing arts while remaining in the library realm reveals multiple research studies using ethnographic methods, with the University of Rochester's two undergraduate research studies as prominent exemplars. ${ }^{9}$ The trained anthropologist leading the Rochester studies used a variety of methods, including photo elicitation, to comprehensively examine undergraduate student work inside and outside the library. In both Rochester studies, photo elicitation was employed in the standard manner already described: subjects took photos per a provided list of prompts, then discussed the photos with a researcher in an interview setting. Finally, the research team analyzed the gathered data. The first Rochester study focused on the common student task of writing research papers, and the second broadened the focus slightly to include related activities like studying and doing homework. Neither study included graduate students. Furthermore, dance and music students were particularly absent because the university offered only a dance minor, and the main music program (the Eastman School of Music and its Sibley Music Library) was on a separate campus excluded from the study. ${ }^{10}$

\footnotetext{
${ }^{7}$ Hursh and Avenarius defined multitasking as using multiple technologies, with print materials being considered a type of technology.

${ }^{8}$ Hursh and Avenarius did not collect data on subject degree program or area of study, but the exclusion of dancers and doctoral students can be confidently inferred from other collected data about the study population and subjects. The study occurred at a branch music library where music students and faculty were the stated primary users. In the exploratory phase, observers recorded apparent age of observed patrons, and most were identified as being in the eighteen-to-twenty-five year age range, thus presumably students (Hursh and Avenarius, 95-96). Regarding dancers, dancers were not among the music library's primary users, but the university did offer undergraduate degrees in dance and the music library housed the university's sound recording collection. Anecdotally, dancers do use the library, so some dancers were likely included in the study, but their status as dancers was not recorded in any way. (David Hursh, email message to author, April 28, 2015.)

${ }^{9}$ Nancy Fried Foster and Susan Gibbons, eds., Studying Students: The Undergraduate Research Project at the University of Rochester (Chicago: Association of College and Research Libraries, 2007); Nancy Fried Foster, ed., Studying Students: A Second Look (Chicago: Association of College and Research Libraries, 2013).

10 The University of Rochester did have a small music department on the studied campus.
} 
The second Rochester study's published findings included a list of all published library photo elicitation studies through $2012 .{ }^{11}$ These six other photo elicitation studies, like the two Rochester studies, largely focused on general undergraduate student populations. Only three of the eight studies included graduate students in any way, ${ }^{12}$ and none focused on music or dance. Some studied institutions did include music and/or dance programs, so it is possible music or dance students were included incidentally, but no published research discusses any music or dance student-specific findings. No additional library photo elicitation studies have been published since 2012. ${ }^{13}$

This article presents the first published results of a photo elicitation study conducted with university music and dance students. It is the first ethnographic library study to explicitly include dancers and one of only a few library photo elicitation studies to include graduate students. The study's main goal was to inform planning of UMKC's new arts campus. Other goals were to identify changes that could be implemented in current UMKC spaces and services and to serve as a case study contributing to knowledge about university music and dance students. The present article focuses on this research's contributions as a case study, particularly regarding: (1) discovering and obtaining music and dance works; (2) study spaces and sound levels; (3) forces of habit and the implications for student library use; and (4) library-related findings regarding practice rooms and classrooms.

\section{Methodology}

The study was built around twenty photo prompts, some adopted or adapted from previous photo elicitation studies ${ }^{14}$ (Figure 1). Previous photo elicitation studies focused on general student study, research, and paper-writing, usually at the undergraduate level. In contrast, this study focused on music and dance students at all degree levels. Therefore, many prompts targeted performing arts-specific activities, especially practice, rehearsal, and other encounters with music and dance works.

\footnotetext{
${ }^{11}$ Judi Briden and Sarada George, "Picture My Work," in Studying Students: A Second Look, ed. Nancy Fried Foster (Chicago: Association of College and Research Libraries, 2013), 42.

${ }^{12}$ Studies including graduate students were: Lynda M. Duke and Andrew D. Asher, College Libraries and Student Culture: What We Now Know (Chicago: ALA Editions, 2011); Tracy Gabridge, Millicent Gaskell, and Amy Stout, "Information Seeking Through Students' Eyes: The MIT Photo Diary Study," College \& Research Libraries 69, no. 6 (2008): 510-522; Sao-Chen Lin, "Perceptions of United States Academic Library Services of First-Year Graduate Students From Taiwan: A Photo-Elicitation Study" (PhD diss., The University of Wisconsin-Madison, 2006).

${ }^{13}$ Study authors conducted a comprehensive review of the library literature and found no additional published photo elicitation studies through April 2015.

${ }^{14}$ The University of Rochester's two studies particularly served as models: Judi Briden, "Photo Surveys: Eliciting More Than You Knew to Ask For," in Studying Students: The Undergraduate Research Project at the University of Rochester, ed. Nancy Fried Foster and Susan Gibbons (Chicago: Association of College and Research Libraries, 2007), 41; Judi Briden and Sarada George, "Picture My Work," in Studying Students: A Second Look, ed. Nancy Fried Foster (Chicago: Association of College and Research Libraries, 2013), 43.
} 
1. A place where you feel most productive

2. A place where you practice/rehearse

3. Something weird

4. Stuff you carry with you every day

5. Your music collection

6. Your desk

7. How you stay organized

8. A place where you socialize

9. A great place to listen to music

10. A place where you study

11. A classroom you like

12. A piece of music that you like

13. A place you like to go to in the library

14. Cool technology

15. Something every Conservatory freshman should know about the library

16. A place you feel lost

17. How you recently discovered a piece of music that you like

18. Something you can't live without

19. The night before a big assignment is due

20. Your favorite part of the day

Figure 1. Photo elicitation prompts.

The study retained the holistic approach of previous photo elicitation research by carefully designing prompts to elicit information on work or activities the library could or should support, while including only two prompts that explicitly mentioned the library: "A place you like to go in the library" and "Something every Conservatory freshman should know about the library." The study even included a few prompts designed primarily to whet creative juices, like "Something weird" and "Your favorite part of the day." Some prompts were intentionally vague, allowing researchers to explore subject interpretations and investigate aspects most important to subjects. For example, the prompt "your music collection" could easily mean either notated ${ }^{15}$ or recorded ${ }^{16}$ music, and subjects did, indeed, interpret the prompt differently. To protect privacy of both subjects and other people, the study excluded prompts likely to elicit photos of people, and researchers explicitly instructed subjects not to include identifiable people in their photos.

Because informing planning for UMKC's new arts campus was this study's primary goal, the subject population consisted of current students in UMKC's Conservatory of Music and Dance. This tightly defined population allowed for targeted subject recruiting, and all potential subjects were invited to volunteer via an email distribution list for current conservatory students. Additional recruitment methods attempted to increase volunteer response: an email to all conservatory faculty members, flyers posted in library and conservatory spaces, social media posts, and engagement with the Conservatory Student Association. As an incentive, selected subjects received a \$20 Amazon.com gift card upon successful study completion. Recruitment

\footnotetext{
${ }^{15}$ A variety of terms are both more common and more ambiguous than "notated music," including: "sheet music," "scores," and "printed music." All these other terms may mean "notated music" but may also refer to a particular subset of "notated music." Therefore, the term "notated music" will be used in this article, except (a) when one of the more specific terms is appropriate, and (b) in direct quotes from subjects.

16 Throughout this article, "recorded" encompasses both audio and video recording.
} 
took place over approximately two weeks in Fall 2014, scheduled to occur a few weeks into the fall semester and thus after the hectic period accompanying the academic year beginning, but early enough that selected subjects would complete study participation before late semester obligations set in.

This qualitative case study included six subjects, an amount comparable to previous library photo elicitation studies, which ranged from five to thirty-two subjects, with most consisting of eight to twelve subjects. ${ }^{17}$ Furthermore, the number of subjects was determined via case study logic, rather than statistical sampling. ${ }^{18}$ When using case study logic, "a good rule of thumb is to continue interviewing research subjects until no new data themes emerge - at this point you have probably reached "saturation" on your topic, and have a picture that begins to reflect a range of responses present in your population." "19 When planning the study, expanding the number of subjects to twelve was left open as a possibility, but, in the end, the study was considered complete after the initial six subjects. As this study progressed, major themes became clear by appearing with regular frequency. Though the study did not reach the point of no new emerging themes, the research team determined that the information potentially gained by interviewing additional subjects would likely not be in proportion to the needed effort. Furthermore, the team employed other methods to achieve additional saturation: a separate non-random, informal exercise with ten conservatory students, ${ }^{20}$ input from a ten-member co-viewing group, and input gathered informally, but systematically, from faculty and students in other parts of the architectural planning process. ${ }^{21}$

Nonetheless, given the small number of subjects, it was important to ensure the study included students with a comprehensive range of academic foci, so volunteers were stratified in two ways before sampling. ${ }^{22}$ The first stratification was area of study. Conservatory programs were grouped into six areas of study: vocal and choral; instrumental; dance; composition; musicology or music theory; and music therapy or music education. The second stratification was degree program, with degrees grouped into two categories: undergraduate and graduate. In order to facilitate stratification, all volunteers were asked to provide their degree program and area of

\footnotetext{
${ }^{17}$ Specific sample sizes of previous academic library photo elicitation studies are as follows, ordered from smallest to largest: five subjects (Lin, 2006), iv; eight subjects (Briden, 2007), 42; ten subjects (Briden and George, 2013), 42; ten subjects (Delcore, et al., 2009), 10; twelve subjects (Keller, 2012), 1; 32 subjects (Gabridge, Gaskell, and Stout, 2008), 510. Hobbs and Klare (2010) did not report their sample size.

${ }^{18}$ Mario Luis Small, “'How Many Cases Do I Need?': On Science and the Logic of Case Selection in Field-Based Research,” Ethnography 10, no. 1 (2009), 24.

${ }^{19}$ Andrew Asher and Susan Miller, So You Want to Do Anthropology in Your Library?: Or, A Practical Guide to Ethnographic Research in Libraries (Illinois: ERAIL Project, 2011), 12. http://www.erialproject.org/wpcontent/uploads/2011/03/Toolkit-3.22.11.pdf

${ }^{20}$ As a pre-planning phase of this research, ten music library student assistants individually and informally brainstormed on the prompt "You're planning the ideal library for YOU. Describe it. What is it like? What does it have?" While not part of the formal study, similar themes emerged in collating and analyzing the 108 ideas brainstormed. There was no overlap between members of this informal group and the six study subjects.

${ }^{21}$ The architectural team conducted various surveys and focus group sessions, sharing selected themes of their findings with building committee members, including the research team's principal investigator. As with the preplanning phase brainstorming, the results were not statistically valid, but the themes were strikingly similar to those uncovered in this formal study.

${ }^{22}$ Stratified sampling divides the population into sub-populations, or strata, thus ensuring important variables (in this research, academic foci) are represented.
} 
study. Volunteers who indicated multiple areas of study were assigned to their self-identified primary group.

At the end of the recruitment period, the principal investigator selected volunteers to become study subjects. The volunteers were grouped by area of study, then numbered. A random number generator was used to select a subject from each area of study. In order to simultaneously satisfy the second stratification (degree program), once three subjects were selected in a single degree program group (i.e. graduate or undergraduate), all remaining volunteers in that degree program group became ineligible for selection as subjects. One small adjustment was made to the planned stratification: despite broad recruiting, there were no volunteers from musicology/music theory, the conservatory's smallest area of study. To reach the desired study size of six subjects, two subjects (one graduate, one undergraduate) were selected from volunteers representing instrumental performance, the conservatory's largest area of study.

The principal investigator contacted the selected volunteers and asked them to become study subjects. All contacted volunteers initially agreed to be subjects, though one subject dropped out after the initial meeting but before submitting photos. In that case, a replacement subject was selected from the remaining volunteers, again randomly but to meet the stratification criteria detailed above.

Each subject met with the principal investigator to discuss the study, provide consent, receive a photo prompt list and instructions, and schedule a follow-up interview one to three weeks in the future. Subjects could take the photos with their own device or a provided disposable camera. As expected, all subjects opted to use their own device, usually a camera phone. Subjects were instructed to name their files with the corresponding photo prompt number and email them to the principal investigator by a specific deadline a few days before their interview. In the end, some subjects needed a little extra time to submit photos, and the ease of digital transmission allowed the principal investigator to extend photo deadlines without rescheduling the interviews.

The interviews lasted approximately one hour and were conducted by two interviewers with the subject in a library conference room. Morae ${ }^{23}$ usability testing software facilitated video and audio capture of the subject and interviewers plus screen capture of the computer used to view the photos, including recorded mouse movements. One interviewer took the lead role while the other served as a back-up, including asking follow-up questions. The main body of the interview was intentionally unscripted and open-ended, with initial questions along the lines of: "What is this?"; "Tell me about [this detail or aspect of the picture]"; or "Tell me how this photo represents [the photo prompt]." Follow-up questions were based on subject responses, and the conversation was allowed to flow naturally. Indeed, some of the most interesting interview sections came when discussion had veered far from the original photo.

Each subject's study participation ended at the interview's conclusion. The research team's work, however, had just begun. Interview transcription occurred first. Because this was not a

\footnotetext{
${ }^{23}$ Morae usability testing software facilitates simultaneous video/audio and screen capture. It also includes tools for recording and tracking facial expressions and eye movements, data analysis, and real-time remote observation, though these were not used for the present research.
} 
linguistic study, transcriptions were clear and complete but did not represent all linguistic subtleties. ${ }^{24}$ The study's complete transcription guidelines are reproduced in Appendix A.

Once the interviews were transcribed, data analysis began via two complementary methods selected from a toolbox of common ethnographic analysis methods. The first method was group video co-viewing. Co-viewing was not a comprehensive analysis but an initial exploration which used the interviews as a tool for group observation and brainstorming. The ten co-viewers represented a broad range of perspectives, including music librarians and staff, conservatory students, conservatory staff, non-music librarians and staff, architects, and research team members.

After a privacy and confidentiality briefing, co-viewers came together for six co-viewing sessions, one session for each interview. In order to provide a reasonable workload and facilitate scheduling, co-viewers were not required to participate in every co-viewing session, so each session included approximately four to six co-viewers. Co-viewers were provided with an interview transcript to read in advance of the group session, along with a few prompts for possible foci. The principal investigator pre-selected interview sections to co-view, focusing on conversations most closely related to study aims. These pre-selections were adjusted "on-the-fly" during co-viewing based on time constraints and co-viewer requests. In the end, approximately thirty minutes of interview video were viewed in each two-hour co-viewing session. Any coviewer could stop the video at any time and comment. Discussion would then continue, lightly facilitated by the principal investigator, until a natural breaking point. Co-viewers collectively recorded discussion highlights in a real-time shared document. Broadly, discussions centered on: (1) recurring themes, (2) problems, (3) things that worked well, (4) other points of interest, and (5) free-form brainstorming. When a subject's successes occurred outside library spaces and services, co-viewers pondered whether similar solutions could or should be incorporated into library spaces and services.

The second data analysis method deepened the initial co-viewing exploration. The research team systematically analyzed all six interviews, using $\mathrm{NVivo}^{25}$ qualitative data analysis software to code the transcripts for recurring themes and topics, including those preliminarily identified in the co-viewing sessions. Co-viewing themes became the beginning of a controlled vocabulary used for coding. The vocabulary was refined throughout data analysis, with the ultimate goal not being a comprehensive thesaurus, but rather a scheme for categorizing the actual interview content. Therefore, topics mentioned more frequently by the subjects were fleshed out more thoroughly in the controlled vocabulary. NVivo's tagging features (called "nodes") facilitated keeping the vocabulary controlled, as well as creating subcategories as needed. The research team read and re-read the transcripts to identify and code new themes, further explore existing themes, and brainstorm innovative solutions. The Findings section reports library-related

\footnotetext{
${ }^{24}$ For example, the study did not adhere to the subtleties of transcription guidelines like the Baylor University Institute for Oral History's Style Guide (http://www.baylor.edu/oralhistory/doc.php/14142.pdf).

${ }^{25}$ NVivo is a tool especially for analyzing unstructured data. It facilitates organization and analysis, providing tools to create a hierarchical coding system that can evolve and change as the research progresses, then facilitating collation and analysis of instances of the themes. It also includes tools for automated coding, sharing, and exporting and importing data.
} 
discoveries from both co-viewing and NVivo analysis and focuses on recurring themes, areas for innovation, and aspects particularly unique to university music and dance students. ${ }^{26}$

\section{Findings}

This study gathered approximately 120 photographs and over six hours of video-recorded interviews. The data contained a broad array of information about music and dance student lives, but researchers focused their analytical energies on uncovering findings related to library and university spaces and services. For purposes of this article, the scope is further narrowed to library-related findings, which fell into four main areas:

1) discovering and obtaining music and dance works

2) study spaces and sound levels

3) forces of habit and the implications for student library use

4) library-related findings regarding practice rooms and classrooms

Each area will be examined in turn in this Findings section. The examinations will identify and analyze major themes and subthemes, and include data in the form of interview excerpts and student photos. ${ }^{27}$

\section{Discovering and obtaining music and dance works}

Interacting with artistic works is central to the performing arts. Dancers and musicians must find out about, or "discover," works, then obtain them, in order to interact with them. In the current library world, the term "discovery" is heavy with implications because many libraries have implemented "discovery tools" 28 in their quest to improve and modernize their online library catalogs. In this article, the word "discover" refers not to discovery tools but rather to the entire process of encountering something new.

In addition, there are relevant correlations between this study's findings and the Functional Requirements for Bibliographic Records (FRBR). FRBR is based on four user tasks: find ("using the data to find materials that correspond to the user's stated search criteria"), identify ("using the data retrieved to identify an entity"), select ("using the data to select an entity that is appropriate

\footnotetext{
${ }^{26}$ It might be supposed that organizing analyzed data by photo prompt would be preferred to organization by identified themes. In reality, the open-ended nature of both photo prompts and interviews means that organization by photo prompt would result in a disorganized, unfocused report of findings. Organizing findings by themes allows important themes to bubble to the top and then be examined as a coherent group regardless of which particular prompt elicited the relevant photo or interview segment.

${ }^{27}$ Unless otherwise noted, all photographs were taken by study subjects. Likewise, all interview excerpts are drawn from study subject interviews. Study subjects provided consent for non-personally identifying photos and transcribed interview excerpts to be used in professional publications and presentations. Interview excerpts in this article have been transcribed following the transcription guidelines, reproduced in full in Appendix A, and edited for this article per the Chicago Manual of Style. The dash (-) indicates pauses in speech. Ellipses indicate material omitted for brevity and clarity, usually to eliminate either (1) the false starts common to spoken conversation or (2) tangential material unrelated to the topic at hand. Per The Chicago Manual of Style, a period is added before the ellipses when material between sentences is omitted. Material omitted within a single sentence is indicated by ellipses without an intervening period. In this article's interview excerpts, words such as "like" have been tacitly removed for readability when they serve solely as crutch words.

${ }^{28}$ For background, exploration, and specific examples regarding discovery tools, see the "General Introduction" section of: Marshall Breeding, The Future of Library Resource Discovery: A White Paper Commissioned by the NISO Discovery to Delivery (D2D) Topic Committee, (Baltimore, MD: NISO, 2015). http://www.niso.org/apps/group_public/download.php/14487/future_library_resource discovery.pdf.
} 
to the user's needs"), and obtain ("using the data in order to acquire or obtain access to the entity described"). ${ }^{29}$ This study's "discover" activity shares parts of the FRBR "find" task, but may precede the "find" task, because "find" requires the user to have "stated search criteria," while "discover" may begin without stated search criteria, or with only generally stated search criteria, encompassing activities like looking for a new piece to play, skimming through scores for compositional inspiration, or encountering a previously unknown work at a recital. Music and dance students highly valued serendipity in the discovery process, as will be particularly seen in the subsection discussing the browsing experience. The FRBR user tasks "identify" and "select" are present in this study, but the high value students placed on serendipity and discovery resulted in less data regarding identification and selection. This article's use of "obtain" correlates very closely to the FRBR "obtain" task, and study findings emphasize the importance students place on obtaining: it is the ultimate goal.

In many situations, multiple versions ${ }^{30}$ of the work are required for full interaction: for example, a musician might first hear someone else performing a work (the initial "discovery"), next seek out a score and listen to several recordings (thus undertaking the standard FRBR find-identifyselect-obtain user task string), and eventually prepare a performance. In some situations, students only engage minimally in the discovery and obtainment processes. For example, an orchestral musician is informed that the conductor has programmed a piece on an upcoming concert and is subsequently provided with a part from the orchestra's library. The conductor might even share links to or information about recordings or full scores. More frequently, however, students undertake part or all of the discovery or obtainment processes themselves, especially as they move towards becoming independent professional dancers and musicians.

Subjects in this study discovered and obtained music and dance works through numerous sources, including the library, internet downloading (free and fee), internet streaming (free and fee, including subscription services), purchase of physical materials, attending performances, assignments by conductors and studio teachers, word-of-mouth, and a striking number of seemingly random encounters. Data analysis revealed that students favored different sources for notated music than they did for recorded works. Specifically, physical library collections figured more prominently in discovering and obtaining notated music, while online services (often free or fee streaming) were used more frequently for discovering and obtaining recorded music and dance works.

Additional data analysis revealed the underpinnings of this differing choice of sources: six considerations which collectively drove behavior. The considerations were as follows:

1) Availability

2) The browsing experience

3) Convenience

4) Cost

5) Quality

6) Legal and ethical issues

\footnotetext{
${ }^{29}$ International Federation of Library Associations and Institutions, Functional Requirements for Bibliographic Records. Final Report, as amended and corrected through February 2009. http://www.ifla.org/files/assets/cataloguing/frbr/frbr_2008.pdf. FRBR user tasks are detailed in section 2.2. ${ }^{30}$ Or, to use FRBR terminology, multiple "expressions."
} 
Subjects did not place equal importance on each consideration. Availability, including expectations of availability, held a trump card in determining behavior. The next three considerations were also important, and assuming similar availability, usually determined student source choice: the browsing experience, especially facilitation of serendipity; convenience; and cost. The final two considerations figured much less prominently: quality, and legal and ethical issues. Overall, sources which met the needs and desires associated with heavily-valued considerations received the most use.

The following subsections will examine each consideration in turn, weaving in discussion of the extent to which specific sources met the needs and desires behind each consideration. See the "Recommendations" section near the conclusion of this article for suggestions to align library resources more closely with highly-valued considerations, as well as particular student values that librarians and faculty members might attempt to influence.

\section{Availability}

Availability is a basic consideration and easy to overlook. Simply put, a work must be represented in a source in order to be discovered or obtained via that source. Not surprisingly, availability considerations ultimately held the greatest weight in source choice, regularly overriding other considerations. For many years, music libraries held a distinct advantage as sources for discovering and obtaining both notated and recorded music based on sheer availability. More recently, online sources have eroded the library market share. Notated music is now available from free sources like IMSLP ${ }^{31}$ as well as fee-based print-on-demand vendors. Music and dance audio and video are even more widely available online, via free and fee-based streaming and download services like YouTube, Naxos Music Library, Spotify, Pandora, Google Play, and iTunes. As a result, today's students can choose from a plethora of sources, all with different scopes and thus different availability.

Source choice usually begins before a student is certain of availability, and so source choice is actually based on expectations of availability, i.e., the student's perception of a source's scope. Though students are not aware of all sources nor thoroughly versed in their scopes, subjects in this study generally chose and then approached sources with expectations for scope, both when seeking a known work and when browsing for yet-unidentified pieces. For example, a student noted YouTube is a useful source for recently composed music.

Subject: Contemporary music...[is] easier to find...on YouTube than [the] library or somewhere else. Even a music store. You know? YouTube is best place to hear them.

The same student knew another internet source, IMSLP, was a bad option for contemporary scores, instead using the library (plus occasional purchasing) to obtain contemporary music. However, the student regularly used IMSLP for older music.

Subjects also revealed their source scope expectations during interviews when they mentioned particular musical works they had expected to find in the library, but did not.

\footnotetext{
31 The "International Music Score Library Project," also known as "Petrucci Music Library." As of November 24, 2015, IMSLP contained over 333,000 scores representing over 99,000 works. http://www.imslp.org/ (accessed November 24, 2015).
} 
Interviewer: Is there anything about [the symphonic scores section] that you would change?

Subject: ...Not really. There's only been one or two instances, where I did not find a score that I was looking for. I think it was for a Prokofiev symphony, that you guys just happened to not... have a score for. Really, it's very comprehensive.

Another student mentioned Spotify as a source for "obscure" music, though convenience and cost considerations likely also influenced the student's decision, because the particular recording (John Adams's I Was Looking at the Ceiling and Then I Saw the Sky) would also have been available from the library or for purchase.

Subject: Spotify has a lot of really obscure music and I was like, "I'll see if Spotify has it."

When a student expected a work would be available from multiple sources, the student generally began with the source which best aligned with the other five considerations discussed later. However, students were willing to use almost any source to obtain highly-desired works with limited availability.

This willingness to use alternate sources is particularly obvious in subject discussions of UMKC's Marr Sound Archives, a treasure trove of over 300,000 sound recordings in numerous historic formats. Since it is a special collection, the Marr Sound Archives poorly meets student values regarding both the browsing experience and convenience. Physical browsing is not allowed, and access is inconvenient compared to streaming audio or even borrowing CDs from the library's circulating collection: the student must visit the Marr Sound Archives during business hours, request a recording, receive necessary instruction or aid to play the recording, and remain in the archive while listening. Predictably, subjects did not rely on the Marr Sound Archives as their main source of audio recordings. However, two subjects expressed awe and admiration for the sound recordings they did use from the Marr Sound Archives. The first stated:

Subject: There's a lot of interesting things down there [in the Marr Sound Archives] as well. My sophomore year I was in a composition class and I was trying to theme something after- I think it was Hungarian folk music- and they have some of the original LPs of ...Bartok's field recordings. And I- that blew my mind as well that they even had such a thing. So, I got to listen to just field recordings of Hungarian people singing and stuff. That was really cool.

The second subject was likewise happy to find a rare recording in the Marr Sound Archives, even though the archive was clearly not a first choice:

Subject: Obviously you can't check [recordings in the Marr Sound Archives] out, so I will sit down with a score and I'll listen to something as I'm doing... with Final Alice by [Del] Tredici, [with] one of the two records that was in [the Marr Sound Archives] that I can't seem to find on YouTube anywhere. 
Student willingness to use the Marr Sound Archives does not come across as begrudging. The students were so happy to find the desired material that all other considerations melted into the background, reinforcing availability's importance as the most basic consideration in source choice.

Availability has a trump card. Students made initial source choices based on expectations of availability, and were eventually willing to try multiple sources to obtain highly-desired works. In many cases, however, works are available from several sources, and so the other five considerations came into play.

\section{The browsing experience}

Study subjects discussed the browsing experience frequently and in response to a variety of photo prompts. These students clearly valued browsing. To reflect the amount of data gathered regarding this consideration, browsing will be examined in extended detail. This subsection on the browsing experience will begin with an introduction to the concepts of browsing and serendipitous discovery, then examine three aspects of collected data which demonstrate the high value students place on the browsing experience: (1) a preference for the library's physical noted music collection due to an engaging browsing experience, (2) a preference for online sources for recordings encouraged by powerful browsing features in those sources, and (3) subject selections of interesting, exciting library discoveries in response to the photo prompt "Something every Conservatory freshman should know about the library."

Browsing occurs when a person looks without a clear known item in mind, though sometimes the person may browse for material possessing particular characteristics or features. Serendipity is an important part of successful browsing. Every subject in this study mentioned at least one instance of serendipitous discovery. Serendipity occurs in numerous situations and may be totally unexpected, partially expected, or even intentionally planned.

Totally unexpected discovery occurred when, for example, a student heard music blasting from stadium speakers, or decided to investigate a piece mentioned in an encyclopedia article chosen at random for a class assignment. At other times, students recognized they were in a situation where serendipitous discovery might occur, even though discovery was not the primary reason for entering the situation. The most common examples of such situations were concerts, recitals, or studio classes where a live performance sparked interest in a work. Finally, students intentionally engaged in activities for the specific purpose of serendipitous discovery, such as browsing library shelves or clicking "related items" links in online audio and video services. Intentional browsing for notated music and recordings is most closely related to library spaces and services, but all types of serendipity can be encouraged by the library.

Student preference for the library's physical notated music collection was driven by an engaging browsing experience that was particularly valuable for intentional browsing. During intentional browsing, students usually sought to limit or control their browsing by one or more facets or characteristics. Instrumentation and genre were common focusing factors, especially for browsing in the library's physical notated music collection, where Library of Congress classification facilitates such targeting. Even though they did not explain it with a librarian's 
precision, students clearly grasped the basics of classification and valued the browsing experience it provides.

Subject: The way things are organized in the music library, I think, is that it's organized by like sections and types of music. So, it's like all the woodwind quintets are in one area or something.

Another student chose the "symphonic scores" stacks section as "A place you like to go in the library." The interviewer prodded for details of the student's activities and goals when visiting the section, and the student explained:

Subject: Sometimes I go back [to the symphonic scores section] and I just am perusing, am trying to find something that looks interesting. Other times I go back there and I'm looking for a very specific piece.

The student's additional comment emphasizes the value placed on spontaneity and serendipity:

Subject: [If] I'm looking for something specific, I will look it up on the computer. However, otherwise, I'll just kind of wander around. It's like, “OK, it looks like I'm around scores for masses, so, ooh, I wonder if they have Missa Solemnis here."

Other sections of the student's interview made it clear the student regularly used internet sources like IMSLP where full scores for Beethoven's Missa Solemnis could have been obtained. However, the student still used and valued the library's score collection because of the physical browsing experience and corresponding likelihood of serendipitous discovery.

Though students valued the browsing experience classification provides, learning about and utilizing classification presented difficulties. One student selected the ability to read call numbers (though the student didn't know the term "call number") as "Something every Conservatory freshman should know about the library" (Figure 2).

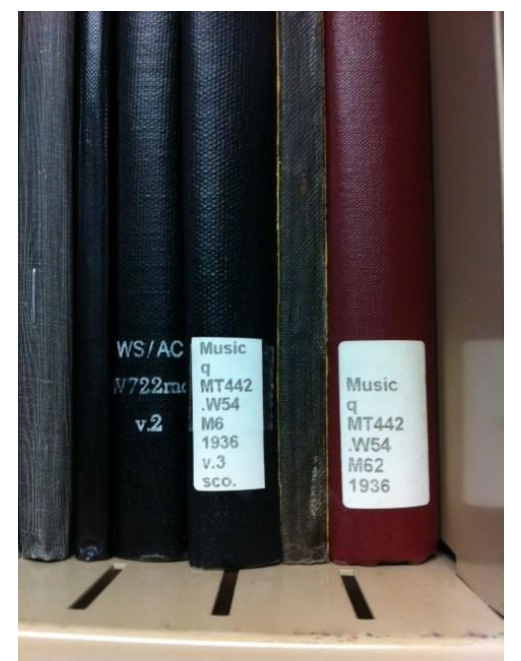

Figure 2. "Something every Conservatory freshman should know about the library": How to read call numbers. 
Subject: They need to know [the code], so they can find the books....Because when I was a freshman...I didn't know how to use the library, [and it was] so difficult to find a book, you know, and I don't want to ask people all the time. So bad! But now, I know all these things....

Interviewer: How did you finally learn how to do this? Did someone teach you, or you figured it out?

Subject: (Shakes head slowly) No...I just figured it out myself.

This student displayed a classic unwillingness to ask for help. A problem obviously exists: a valuable system is in place, yet it is not easy for students to learn about. Furthermore, even those who do know the system are plagued by another browsing problem: way-finding in long rows of thin, pamphlet-bound notated music with few labels, titles, or composer names visible on the spines (Figure 3). One student suggested "It would be nice if the label is... on the edge." Another student mentioned along similar lines:

Subject: It would be nice if there were a little thing that simply said, "Woodwind Quintets." ....and I could go over there and look through the section, look at all the stuff and like, "Oh, this one looks interesting."

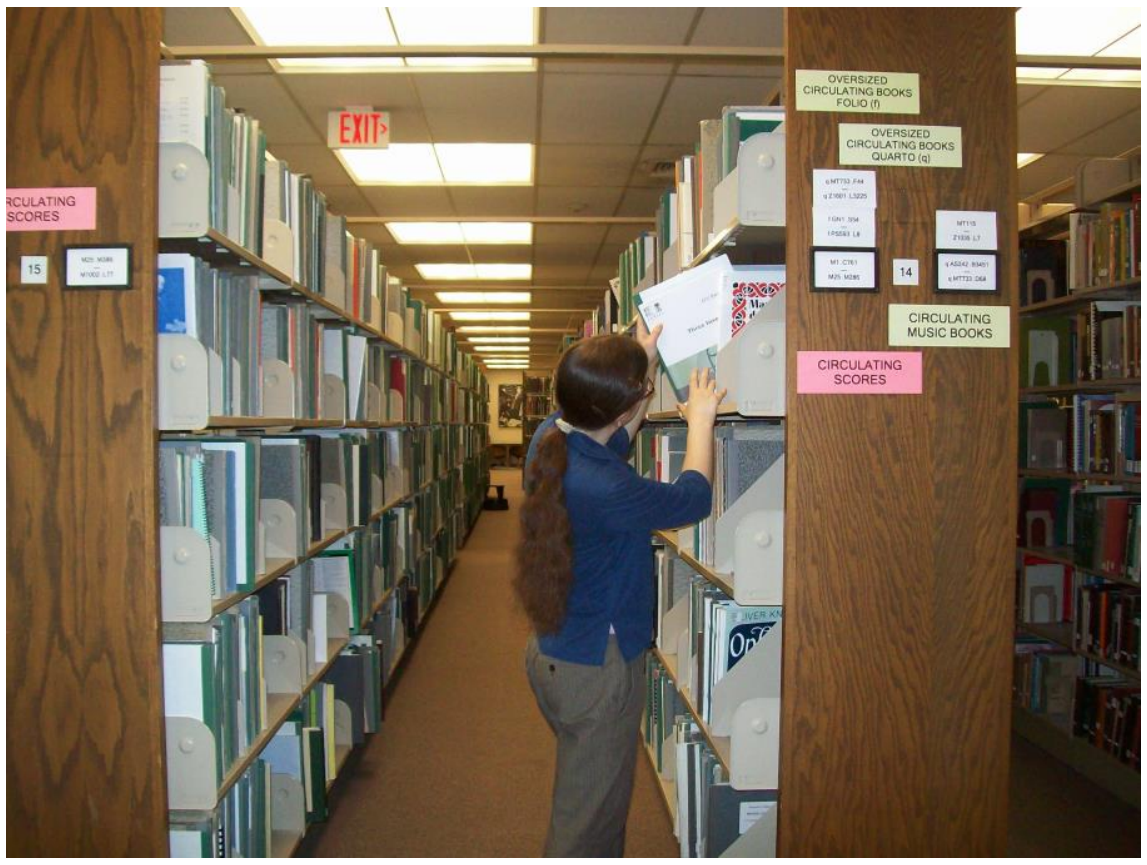

Figure 3. Tipping volumes out to check the call number in long rows of thin, pamphlet bound materials. (Photo courtesy of UMKC Libraries staff.)

Not all browsing was by instrumentation and genre. Indeed, one highly valued intentional browsing situation seemed random at first glance. A composition student photographed the oversize score section as "A place you like to go in the library" (figure 4) and explained browsing for compositional ideas and inspiration. 


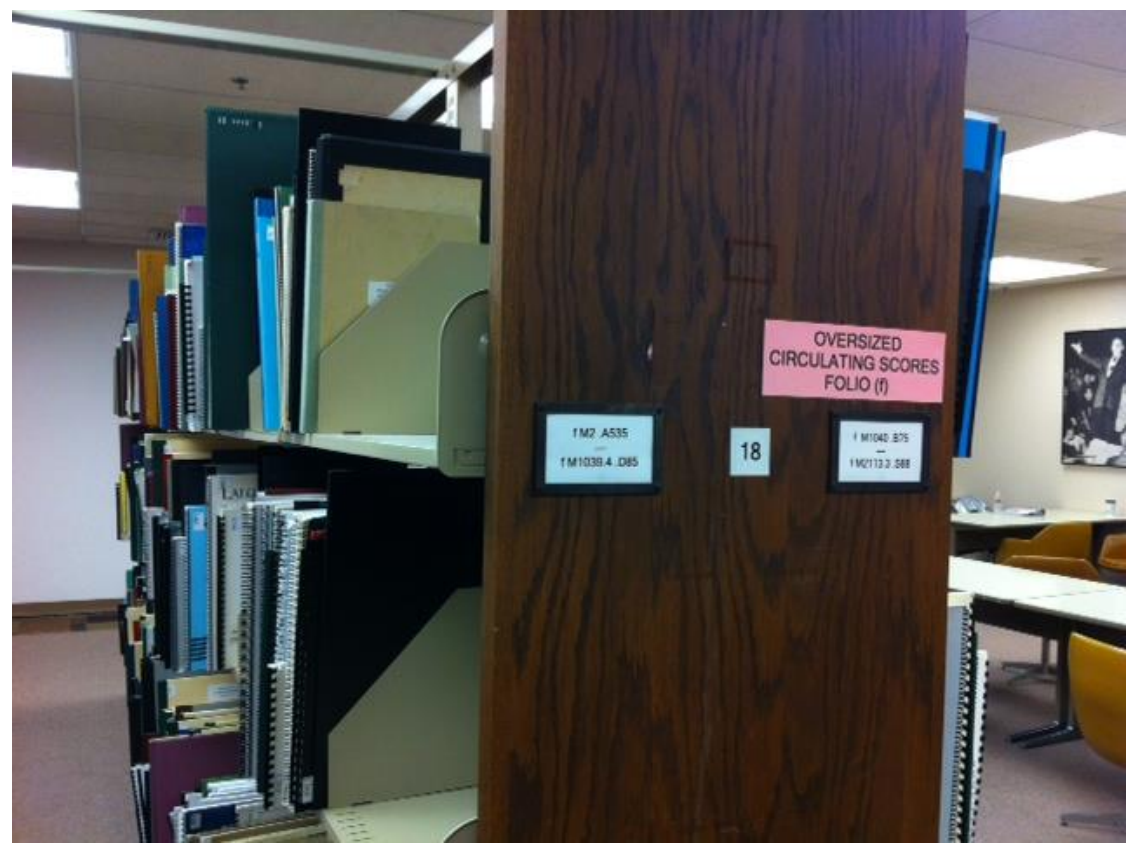

Figure 4. The oversize scores section, where a student intentionally browsed for compositional ideas and inspiration.

Subject: When I need new ideas, I just go to... this shelf, and randomly check the piece, and, like, ah-ha, maybe this one, this one, and bring them home and study.

Interviewer: And you go to this shelf, specifically, the oversize scores?

Subject: Yes...big score[s] can give me more ideas, because I can see the texture.... Piano music can do that too, but, I prefer to see structure. Structure is very important. I can see the shape....

Interviewer: [Is it also because] a lot of the scores in this area too are...twentieth and twenty-first century composers?

Subject: Right, right.

Interviewer: Does that make this especially why you come here, or-?

Subject: Yes....Because, I know Bach. I know Beethoven....But I don't know all of these composers....

Interviewer: Then do you check them out and take them home, or do you usually look at them in the library?

Subject: No....[I just] look at them in the library. I have a piece of paper and then take notes. And then go back home. 
The student specifically preferred the oversize section due to two expectations about source scope (i.e. availability considerations): (1) the way the large scores showed structure and texture, and (2) because pieces by twentieth and twenty-first century composers are concentrated in the section. The student didn't necessarily check the scores out, but examined them in the library, took notes, and went back home to compose. Anecdotally, UMKC library employees have observed other composition students regularly browsing the oversize section, adding weight to this student's use. This use highlights the value of a physically browsable score collection, with nearby tables to spread out and examine large scores.

Librarians create oversize sections merely for logistical and space-saving reasons, so accumulation of large ensemble and twentieth and twenty-first century music in the oversize area is incidental to librarians' original goals in creating the section. Today, some librarians seek to improve the browsing experience by eliminating oversize collections (especially oversize book collections), spacing general collection shelves farther apart to allow "oversize" materials to be interfiled with standard-sized volumes. Therefore, it is important to recognize that oversize notated music collections actually improve the browsing experience, at least for composition students. Indeed, the student had sought out the oversize collection at UMKC after using the oversize section at another institution in similar fashion, and when the interviewer asked for suggestions on improving the oversize section, the student was adamant that it not be changed.

Students also intentionally browse audio and video, but chose online, non-library services which provide a powerful browsing experience via "related items" or "you might like" features, such as YouTube's "Up Next" sidebar of related videos. Computer algorithms powering these features allow them to display audio or video selections sharing qualities with previous selections, thus increasing the likelihood the user will encounter something of interest. The end result is similar to the experience classification facilitates for notated music, but enhanced because the computer algorithms can encompass a greater variety of aspects. This exchange regarding YouTube comes from the same student who placed a high value on browsing oversize scores:

Subject: YouTube...[has] links.... So, if you like this piece, maybe you can just random click on the other piece, and then you find the other interesting music too.

Another student likewise valued serendipitous browsing but used much older technology, specifically a friend's LP collection (Figure 5).

Subject: [A friend and fellow conservatory student] just has a zillion records and a record player and there's lots of good stuff. So, sometimes, I'll just flip through and find some neat things. He has lots of good piano music and also, just, he just likes music in general. 


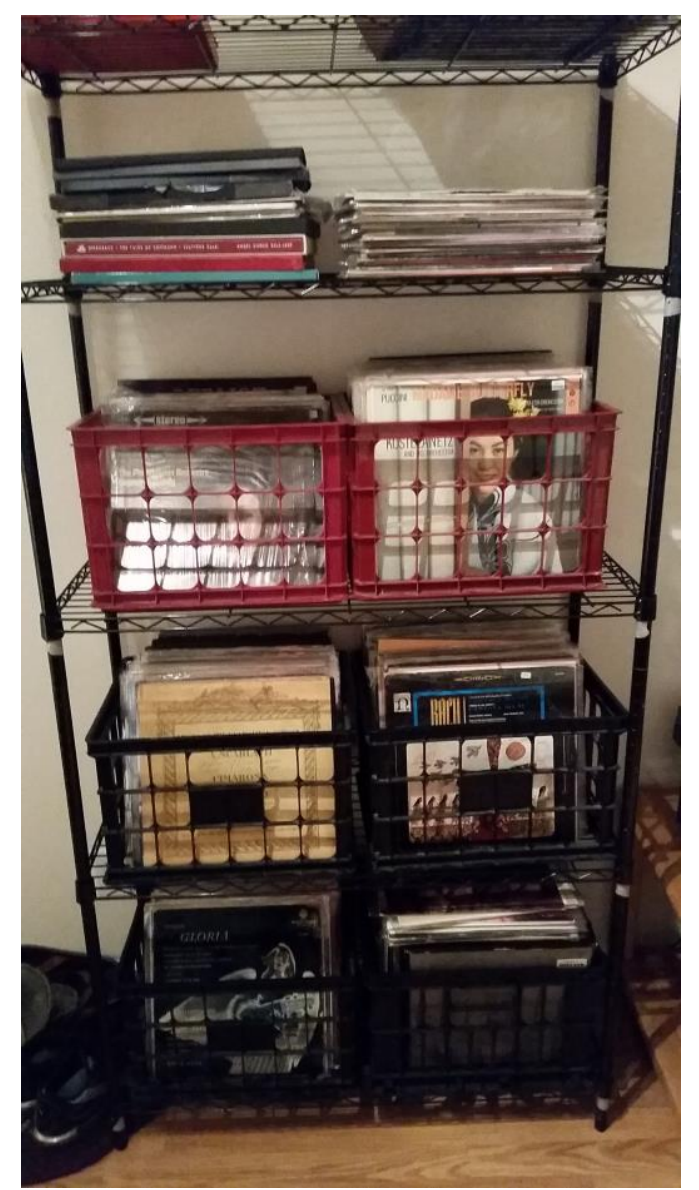

Figure 5. Discovering new music by browsing a friend's LP collection.

In contrast to online browsing experiences as well as the above student's experience physically browsing LPs, UMKC, like many academic libraries, keeps all recordings in closed stacks ${ }^{32}$ and so does not provide students a physical browsing experience for audio and video. Students must locate recordings via the library catalog, which, while an adequate tool for locating known works, does not facilitate serendipitous browsing in the ways websites such as YouTube or Spotify do. Because students valued browsing, it is not surprising they chose sources with more robust browsing options. ${ }^{33}$

Notated music and recording browsing were not the only activities that highlighted the value students place on serendipitous discovery. Student responses to the prompt "Something every Conservatory freshman should know about the library" provide further support for these conclusions. Researchers expected this prompt to elicit photos of important library basics, but in actuality, four of the six subjects instead photographed interesting and exciting aspects of the library. Specifically, the six subject photos represented: (1) ability to use call numbers, (2) a library printing and scanning area, (3) a painting of local jazz musician Bettye Miller, (4)

\footnotetext{
${ }^{32}$ UMKC uses accession numbers for sound recordings and Library of Congress classification for video recordings.

${ }^{33}$ University-provided audio subscription services such as Naxos Music Library (NML) and the Database of Recorded American Music (DRAM) do provide some browsing functionality, including the ability to listen ondemand, thus simultaneously increasing convenience. In fact, during the years 2012-2014, UMKC patrons listened to an average of over 56,000 NML tracks and over 16,000 DRAM tracks annually.
} 
medieval chant books in special collections, (5) the Marr Sound Archives, and (6) that students should know about and read relevant music periodicals.

The first photo has already been examined in the earlier discussion of the importance of physical browsing for notated music. That student photographed call numbers (Figure 2) and emphasized the importance of being educated to use them.

Along even more basic lines, one student photographed the library's printing and scanning area.

Subject: This is the scanning area where you take your stuff to get printed basically. It has literally saved my life on many occasions, "cause I always forget like "crap, that paper was due, I have to go print it" so I'll run to the library, or the computer lab in the student union, but I like this one because it also has a scanner if I have to scan something, and also, it has a lot of staplers and hole punches, and I really like the office-y stuff.

The remaining four students (numbers three through six in the list above) responded to the prompt with photos related to interesting and serendipitous discoveries. The student photographing a painting even voiced a felt obligation to have photographed library basics, but was compelled to choose otherwise.

Subject: I thought it- I thought about it as a random little tidbit. I don't- I mean, I guess I should've like, "This is where you check out books," or something.

Interviewer: No!... There [are] no wrong answers.

Subject: I tried to think of something that- because it blew my mind when I found out what this is. But, we were doing a project in Special Collections about Bettye Miller and someone told us that that was a picture of her. And I was like, "I've been seeing her." You know? Like, when you're in the computer lab and you're like, "Who is that lady?" Like, very fierce. And so, then, when I found that out, I thought that was really cool. And, I was so sad that there was no thing [sic, i.e. no descriptive placard] about her!

Another student photographed an equally fascinating item discovered in the library collections: a medieval chant book (Figure 6).

Subject: This is on the top floor in the Special Collections Department. We have two manuscripts of chant stuff from the $15^{\text {th }}$ Century. I thought that was really cool. ... You can't really tell from the picture, but these books are like, huge. I mean like... this big (gestures with arms) by like that big. And they have these huge wooden covers and everything. 


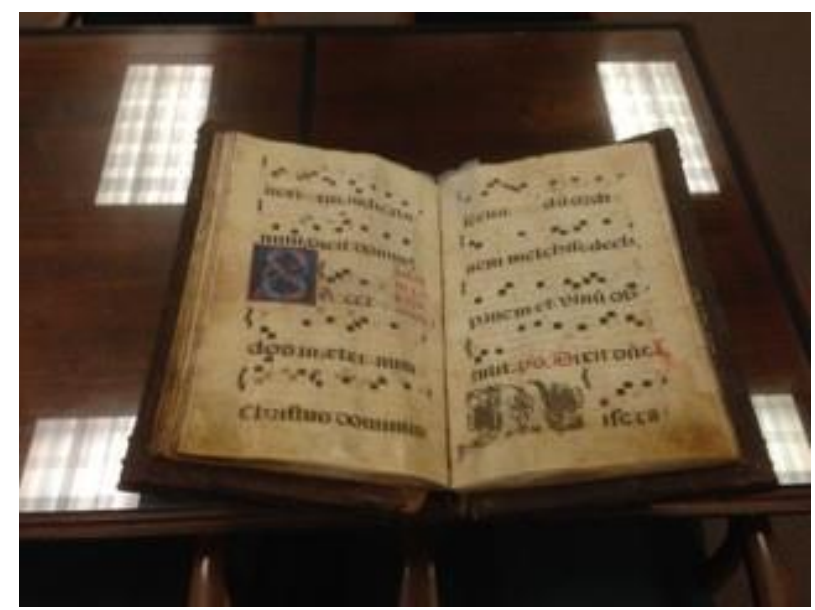

Figure 6. "Something every Conservatory freshman should know about the library": a medieval chant book in special collections.

Along similar lines, a student selected the Marr Sound Archives, and elsewhere in the interview noted listening to particular pieces there. The final student photographed music periodicals, and explained:

Subject: I just thought that music journals are an important thing and people should read them and, so, they should know that they're there at the library at their disposal.

While each subject's photograph was different, their interpretations of the prompt "Something every Conservatory freshman should know about the library" collectively emphasize the value these students placed on serendipitous discovery. Specifically, students looked to the library as a place for discoveries that fascinated them or that specifically contributed to their professional growth and work.

In summary, the browsing experience plays a major role in determining student choice of source, especially when students intentionally sought serendipity. In particular, an excellent browsing experience in the physical notated music collection drove students to use it. For recordings, however, students preferred online sources with powerful, intuitive browsing over the poor browsing experience available for the library's physical recordings collection. Further evidence of the value of serendipitous discovery is found in photographs elicited by the prompt "Something every Conservatory freshman should know about the library." The particular value music and dance students placed on browsing may be unique to these disciplines, or it may simply be more obvious because of the importance of primarily non-text-based content in these disciplines. Now, as in the past, more powerful and varied browsing and search options exist for text-based content than for non-text-based content such as audio, video, and notated music. ${ }^{34}$

\section{Convenience}

Though availability held a trump card and the browsing experience played a strong role, four other considerations affecting student source choice remain to be examined: convenience, cost,

\footnotetext{
${ }^{34}$ A similar situation may exist for other non-text-based disciplines such as the visual arts, where images are very important. However, this study only included music and dance.
} 
quality, and legal and ethical issues. Convenience, like the browsing experience, played a strong role in determining source choice. However, unlike the browsing experience, students often referred to convenience implicitly rather than explicitly.

Implicit reference to convenience was especially characteristic of student discussions regarding source choices for notated music. For example, one student came to the library (a less convenient choice) to browse contemporary scores not available on IMSLP (a more convenient choice), but continued to use IMSLP when possible. Another student stated "I have sometimes gotten stuff off from Schubert Line just because I was lazy and didn't want to go to the library."

Students spoke both more explicitly and more frequently about convenience in relation to listening decisions, for example in this student's explanation of the choice to use Google Play and YouTube:

Subject: I like Google Play or just YouTube, too.... When I'm practicing, if I kind of want to hear something, I can just go on YouTube quick and listen.

Similarly, a student noted previously listening to music loaded on an iPod, but now being able to use YouTube.

Interviewer: Do you have a recording of this on your iPod?

Subject: Yes....But now I can just YouTube them, yeah. Easier.

Convenience and the browsing experience often function together, and sources providing a convenient browsing experience have a high likelihood of use, particularly when students are not searching for a known item. An examination of cost in the next subsection will demonstrate the ways cost considerations interact with both convenience and the browsing experience.

Cost

Like convenience, cost considerations were often implied rather than explicitly stated. Historically, libraries have held an advantage in user considerations of cost since academic library use imposes few additional charges on currently registered students. However, many online sources now available for both notated music and recordings are also free.

Cost was explicitly discussed most frequently in regard to recordings, and is especially relevant in situations where serendipitous browsing is highly valued because it would be expensive to buy large quantities of music just to examine it. This student's explanation of YouTube use exemplifies the reasoning behind cost avoidance when browsing.

Subject: People...[tell] me, "oh, well, you should listen to this sort of piece.” OK, well, I don't want to pay ninety-nine cents ${ }^{35}$ for something that I may not like, so, let's see what the YouTube people have to say about it. And, I've found pieces that both made me really enjoy listening to it, and pieces that I was like "why did I ever press play?" but it is

\footnotetext{
${ }^{35}$ Ninety-nine cents is a common per-track price for internet audio downloads.
} 
a good avenue for finding newer [i.e., new to the student, regardless of composition date $^{36}$ ] pieces of music.

A dance student whose music collection was primarily for background and relaxation purposes also noted the cost factor behind a decision to use Spotify rather than purchasing recordings.

Subject: I would be a very poor person if I bought all my music. So, I utilize internet radio and Spotify is my favorite. Because you can basically just type in whatever you want to hear.

While the above statement emphasizes costs, availability expectations were also a consideration, as evidenced by the student's statement that "you can basically just type in whatever you want to hear." This student's comments reinforce the extent to which availability drives student selection of sources to discover and obtain music and dance works.

Though no subject explicitly identified cost as a consideration regarding notated music, subjects mentioned many uses of library and internet notated music collections which saved them money in comparison to purchasing printed music. One student explained a choice to use IMSLP instead of making purchases as primarily due to cost considerations:

Interviewer: Do you have a separate collection of scores that's your violin music that you're working on or have worked on? How do you manage that?

Subject: Typically, I just go out to IMSLP, and I just print off what I need. I don't go ahead and buy entire volumes of pieces. It's like, "Well, I don't know if I'm ever going to play twenty or thirty percent of these things," so, whatever I do get, I probably just download it.

Cost was thus an influential factor in student decisions, especially when the cost differential between two potential sources was high: in such situations, students regularly chose the option which incurred lower costs. In situations where the basic consideration of availability was met, the browsing experience, convenience, and cost together drove most student choices of sources. The remaining two considerations (quality and legal and ethical issues) had much less impact but are worth examination precisely because of these lower levels of influence.

\section{Quality}

Quality considerations here encompass skill and qualifications of performers and editors as well as sound and printing quality. In particular, both convenience and cost often overrode quality when students chose a source. In fact, most conclusions regarding student valuation of quality must be inferred from lack of mentions of the consideration. Three students did briefly mention quality issues related to: (1) notated music, (2) dance video, and (3) recorded music.

The near lack of mention of editorial issues for notated music is especially significant given the pervasive use of IMSLP, a source which, due to the public domain requirement, tends to contain

\footnotetext{
${ }^{36}$ The interviewer clarified: "You mean newer like, composed recently?" and the subject answered "Yeah...newer as in composed recently, or maybe just, a piece...by an old composer you've never heard."
} 
older editions which may not reflect modern scholarship. In addition, bad scans of heavily marked music detract from some IMSLP offerings. ${ }^{37}$ Indeed, the only student who mentioned quality as a factor in selecting notated music did not explicitly mention IMSLP and focused more on "the right key and the right everything":

Interviewer: So, you mentioned that you had a lot of music from the library. Is there any other place that you get music? Does that pretty much cover it?

Subject: Pretty much the library. I have sometimes gotten stuff off from Schubert Line just because I was lazy and didn't want to go to the library. But, really, there's nothing that you can get online. You would have to purchase it.... [And] it's always nicer to go to the library and make sure you're getting the right key and the right everything.

The most explicit mention of editorial or performance quality came from a dance student who specified performance quality as major factor in selecting ballet videos. The student evaluated performance quality based on the reputations of individual dancers and ballet companies.

Interviewer: You said your friend finds all these videos. How does she find them? Do you have any idea?

Subject: Well, the bigger companies like ABT [American Ballet Theatre] and New York City Ballet, they will sell them, from their website or their store, and we always look for specific dancers that are dancing the roles that we like. But yeah, you can buy them online. We always just make sure it's a good one. We don't get a crappy one.

Interviewer: How do you make sure it's a good one and not a crappy one?

Subject: Look at the company that did it, maybe. There's like, the "Big Five" [top dance companies]... [if it's danced by a top company], you know it's gonna be a good one because they only hire the best.

Finally, one student mentioned sound quality of recordings, asserting a preference for Google Play over YouTube due to better sound quality, though the student (per statements elsewhere in the interview) still used YouTube in some situations. So, even though quality was an influential factor, it did not single-handedly drive the student's choice of source.

Subject: My friend told me that YouTube decreases the sound quality of their videos so that they can have the high quality video. So, Google Play, basically, just has anything you could want, pretty much. I'll just be, like, "Hmm. I want to hear this song," and it's there.

\footnotetext{
${ }^{37}$ Library collections can also have quality problems, containing, for example: (a) public domain notated music, including notated music from reprint publishers like Dover or Kalmus; (b) older editions of notated music, both incopyright and public domain; and (c) heavily marked notated music, particularly if the library does not vigilantly erase markings when materials are returned. For a detailed examination of IMSLP, see Casey A. Mullin, "International Music Score Library Project/Petrucci Music Library (Review)," Notes 67, no. 2 (December 2010), 376-381.
} 
This student had obtained Google Play in conjunction with an Android phone (a consideration of convenience) and it is also obvious from this quote that Google Play had sufficient availability of the music the student sought.

Though study subjects barely mentioned quality issues, it is possible students may consider quality more heavily or often than reflected in this research. The lack of photo prompts targeted at quality issues and a particular characteristic of the study's subjects may have skewed results: three of the five music students were in their first semester at UMKC, whether as freshmen, transfer students, or incoming graduate students. Perhaps longer-term students would answer differently. On the other hand, all the graduate students already held degrees in music, and this seems not to have affected their choices and values. What these findings do reveal is this: when students talk about discovering and obtaining music and dance works, and especially when they discuss notated music, quality does not rise to the top of their minds. Availability, the browsing experience, convenience, and cost are the chief draws.

\section{Legal and ethical issues}

Legal and ethical issues were, like quality, noteworthy for the infrequency with which students mentioned them. Moreover, when students did mention ethical or legal issues, they quickly dismissed the considerations, or at best displayed incomplete knowledge of admittedly complex issues, such as this student's explanation of a choice to purchase a score rather than download a copy from IMSLP.

Interviewer: Ok, so you actually bought a score of [Schoenberg's Verklärte Nacht], instead of just using IMSLP?

Subject: Because...Schoenberg's music is not yet public domain.... Now [it] is past fifty years already...so, you can find some of his stuff on IMSLP. Maybe this piece also. But, like five years ago, you couldn't.

The student demonstrated a basic but incomplete and partially inaccurate awareness of IMSLP's scope as well as the copyright issues behind IMSLP limitations. In particular, while numerous scans of notated music for works by Arnold Schoenberg (1874-1951) have been added to IMSLP in recent years, most are still not in public domain in the United States, even though the works are in the public domain of other countries.

Another student dismissed legal considerations as "nonsensical" in explaining a decision to rip a CD track:

Subject: If it's like, I just want one track, I'll maybe find the CD at the library. And I'll get the one track. I know it's- I think that's technically illegal, but buying an entire CD for one track seems a little bit nonsensical sometimes.

A third student failed to mention legal or ethical issues at all when explaining regular copying of printed music for study and performance: 
Subject: I normally just go to the library and make copies of stuff that I need. Very rarely do I ever [buy books of music]. I mean, it's nice to have the books. But, books get ruined.

Though some described uses may have been legal and fair, there was no evidence in the interviews suggesting students had included legal and ethical factors as a significant part of their decision-making process. Instead, availability, the browsing experience, convenience, and cost drove their choice of sources.

\section{The library and student source choice}

Student choice of source was driven by the value students assigned to six considerations in combination with the extent to which individual sources met the needs and desires behind the most heavily valued considerations. In the past, libraries held a strong advantage in availability, the consideration which regularly trumps all others. Today, however, music and dance works are available from many sources. Because of wide availability, student decisions were largely determined by the browsing experience, convenience, and cost. Sources which combined availability, an excellent browsing experience, convenient access, and were free or very low cost were almost certain to be used. Quality and legal and ethical issues were much less influential considerations.

Regarding source choice for notated music, students preferred the library's physical notated music collection because it combined a high likelihood of availability, a good physical browsing experience, and zero cost. It is less convenient than online sources like IMSLP, but IMSLP has lower availability of contemporary music and modern, in-copyright editions of music of all eras, a less robust browsing experience, and potentially higher cost if a student needs to print physical copies. Thus, students used both IMSLP and the physical library collection, varying their source choice based on the particular situation. Quality considerations and legal and ethical issues factored less into student decisions.

For recordings, students frequently turned to online sources. The library collection and online services provide similar availability for recordings, with online sources actually having an edge in the subcategory of very recently composed music. While materials in the library collection often are of higher performance and sound quality, particularly compared to YouTube's offerings, convenience and the browsing experience regularly overrode quality considerations. Students frequently ignored legal and ethical issues when using both library collections (unreservedly ripping $\mathrm{CDs}$ ) and online sources (rarely investigating or even considering the legality of posted materials.)

\section{Study spaces and sound levels}

This study's second group of findings concerned study spaces and sound levels. Academic libraries today often provide an assortment of spaces to support different learning styles and types of work. In general, these spaces fall into two categories: "quiet" areas, used by individuals who work best with minimal activity or noise around them; and "loud" areas, used by groups and by individuals who work well with noise and activity surrounding them. Libraries may create spaces at finer gradations along the noise continuum, for example "semi-quiet" areas where quiet group collaboration is allowed and "ultimate quiet" rooms where absolutely no noise is allowed. In general, the quieter a space becomes, the less conducive it is to group work. 
This research project confirmed that music and dance students, like students in general, value quiet and loud spaces. However, quiet and loud spaces alone did not meet the needs of study subjects. Specifically, music and dance students had an academic need to listen to music (i.e. make sound) but simultaneously focus and be free of other distractions, particularly other sounds. This discipline-specific factor resulted in a need for a third type of space, which researchers termed "soundproof" space. This section will focus first on standard quiet and loud spaces, then move to the unique soundproof space, considering both individual and group study throughout. The section will conclude with overall observations about study space, including locating study spaces within a facility, balancing different space types, and electrical outlet needs.

\section{Quiet space}

Beginning with quiet spaces: most students need a space where they can block out distractions and "zone in" on a task at hand. For some students, distraction-blocking requires quiet plus minimal surrounding activity. These students usually work in either their own living spaces or quiet study areas of a library. One student obviously preferred the distraction-free environment of a studio apartment with no roommates and closed windows, photographing it as "a place you feel most productive" (Figure 7).

Interviewer: This is a place where you feel most productive.... Tell me about this space....

Subject: Basically, it is my room. I work here most of [the] time. Most of the day or at night.

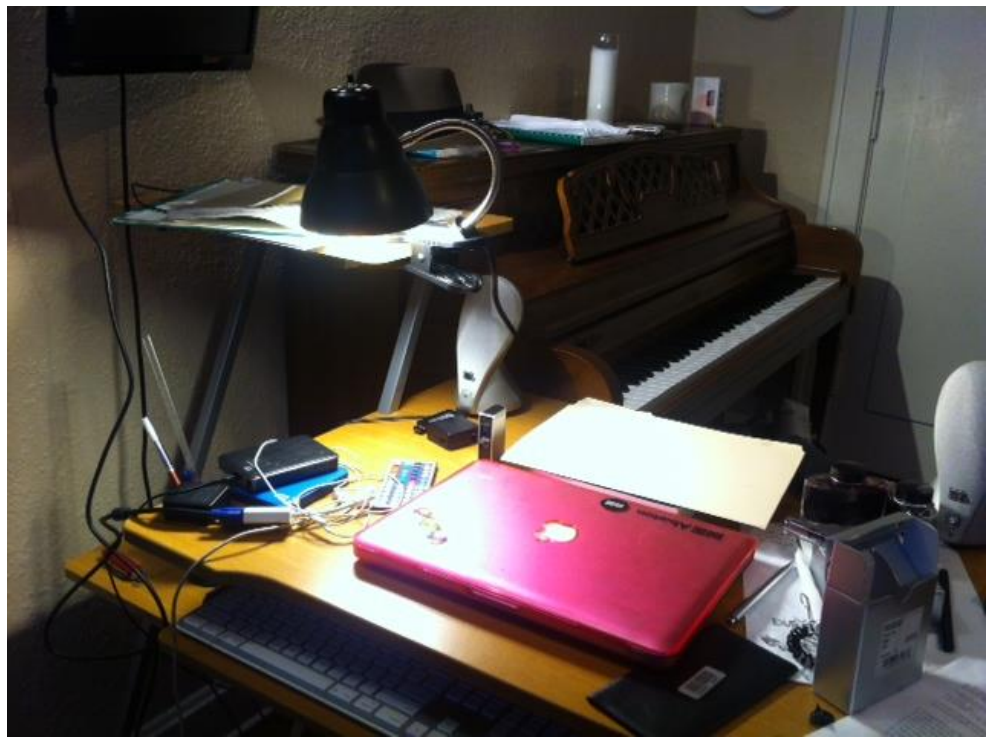

Figure 7. A distraction-free studio apartment, one student's "A place you feel most productive."

Another student, who shared a house/apartment with roommates, selected a secluded bedroom corner for intense study (Figure 8).

Subject: That's just the floor in front of my bed, to be honest....Somehow I just end up there when I'm studying for things because it's...even more isolated than the sofa area [a 
shared "living room" type space]. So, it's like, if I really need to focus on learning something that I've forgotten or getting ready for a test, or learning- doing something specific, I'll go there since it's really private and everything.

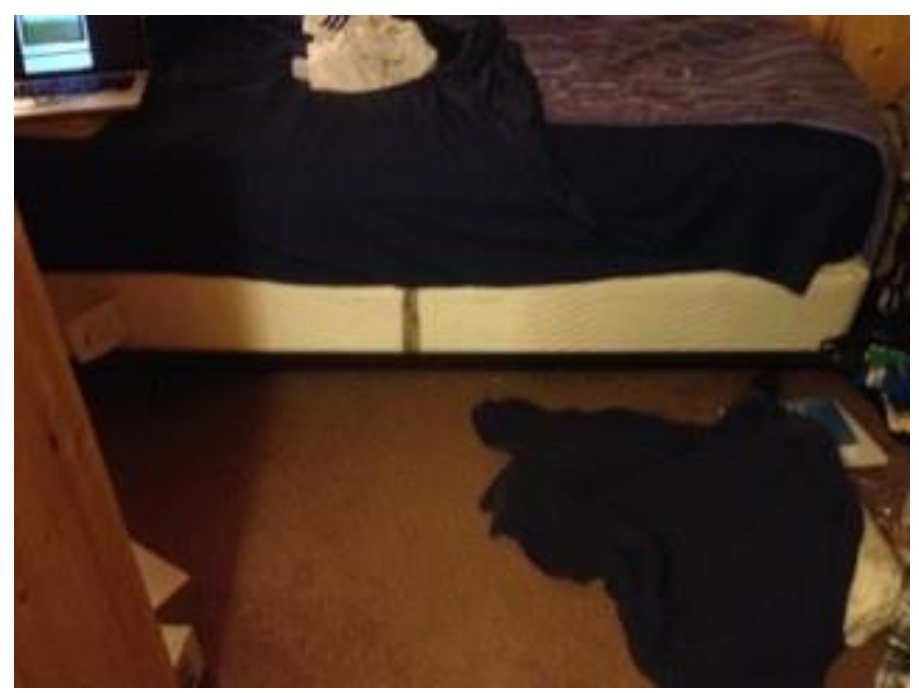

Figure 8. A secluded bedroom corner, which one student selected as a place for intense focus.

While these two students valued areas that were not only quiet but also physically isolated from other people, some students benefit from being in a group of quietly working people. One student valued the library for paper-writing (an individual activity), particularly the focus created by being around other similarly engaged people. However, the discipline-specific sensitivity to sound is obvious: the same student avoided on-campus practice rooms, which might provide the same sense of being around others hard at work. The difference was due to the differences in these kinds of work and especially the need to focus on sound when practicing.

Subject: I have a computer at home but I find that I can get distracted easily. So, if I need to write something I'll come to the library to write that....I'll use the computers [in the library] because I find that I can focus more just in the library. Plus, I like libraries.

Interviewer: So you find that you can focus on writing a paper better in the library but your practicing works way better in your home....Do you have any ideas of why that difference is?

Subject: ...In the library, everybody else is also putting their energy and their focus into [paper writing and similar activities.] And it's a lot easier for me to be able to be with the sounds of the library than it is to be able to be with the sounds in the practice room.

This student's comments introduce musicians' particular sensitivity to sound. This sensitivity will be explored further in the discussion of soundproof spaces. For the present, the conclusion regarding quiet study spaces is clear: most students value access to spaces where they can block out distractions. Therefore, quiet, low-distraction spaces should be included in library and campus facilities. 
Loud space

The discussion now moves to loud spaces. A dance student expressed a textbook example of the type of group work loud areas facilitate, describing a group study session in a loud library area optimized for group work.

Subject: This was studying for our...class, because [a large group of students] are required to take this specific [course]. There were like, eleven of us or something, so we filled out the table pretty good.... It was actually really nice to have such a big group of people all shouting- not shouting, saying- their opinions or ideas on- the different music that we had to dissect.

Interviewer: ...From beginning of that session to the end, did it solve the concerns that you had? Did you figure everything out?

Subject: For the most part. When you have that many people together, it's hard to really stay on track, if you know what I mean, like, the distraction of, especially like Rocket Coffee [i.e. the library's Roobot Café] being right there. But no, I think we did pretty well. We got done what needed to be done, and it helped us feel more confident for our test that we had that following Monday. Yeah. Study sessions: highly recommended.

Loud spaces optimized for groups also provide a place for individuals who work best with activity and sound around them: the surrounding group activity supplies the white noise. Including some individual (but still generously-sized) furniture in loud study areas will optimize space usage because individuals can be present without monopolizing space that could be used by an entire group.

Loud spaces often support both social activity and study. Socially-oriented activity should not be dismissed as "less important." While the socializing was sometimes recreational, it often had scholarly community-building aspects seamlessly blended in, as one student explained.

Subject: Me and the other composition students, we all hang out there, in the PAC [Olson Performing Arts Center, one of the buildings housing conservatory spaces], especially around where they have the couches and that room right by the stairs where you go up.... It's kind of like a hidden room, but it's not a hidden room. ... We especially like to sit down in there just, for hours, and we talk, and exchange ideas, and, also, it's where I usually end up meeting people for meetings, like my composition mentor, a pianist who's doing a piece of mine. So it's kind of where I socialize for fun, and then socialize for, OK, let's sit down and have professional talk.

Social activity and noise levels may vary in loud spaces depending on the time of day and day of the week. Students may choose different areas at different times, or welcome the change of pace, as did one student who studied in an open, semi-quiet library area.

Interviewer: Do you sit usually at a table all by yourself?

Subject: Yeah, and then normally someone will join. Partway. 
Interviewer: Somebody you know?

Subject: Yeah.....

Interviewer: Do you like that they join you? Or would you wish they sort of wouldn't? I won't tell them what you said.

Subject: (Laughs) It's okay. I generally don't get work done when they're there. So, that's why I do like [that] normally the first hour I'm by myself. And then the second hour, it's kind of nice to have a break. So- You definitely get a lot less work done.

Even though the student "got less work done" in a group situation, the student still looked positively on the "break" provided by having classmates around. Spaces optimized for loud study facilitate changing use better than quiet spaces, because quiet spaces carry an expectation of constant quiet, while more sound level variation is acceptable in louder spaces.

Students regularly equated soft seating, especially couches, with social spaces, with four of the six subjects explicitly photographing or mentioning soft seating in response to the prompt "a place where you socialize." One student expressed the connection between couches and social space particularly bluntly (Figure 9).

Interviewer: What makes this good for socializing?

Subject: It is a couch! (Laughs).

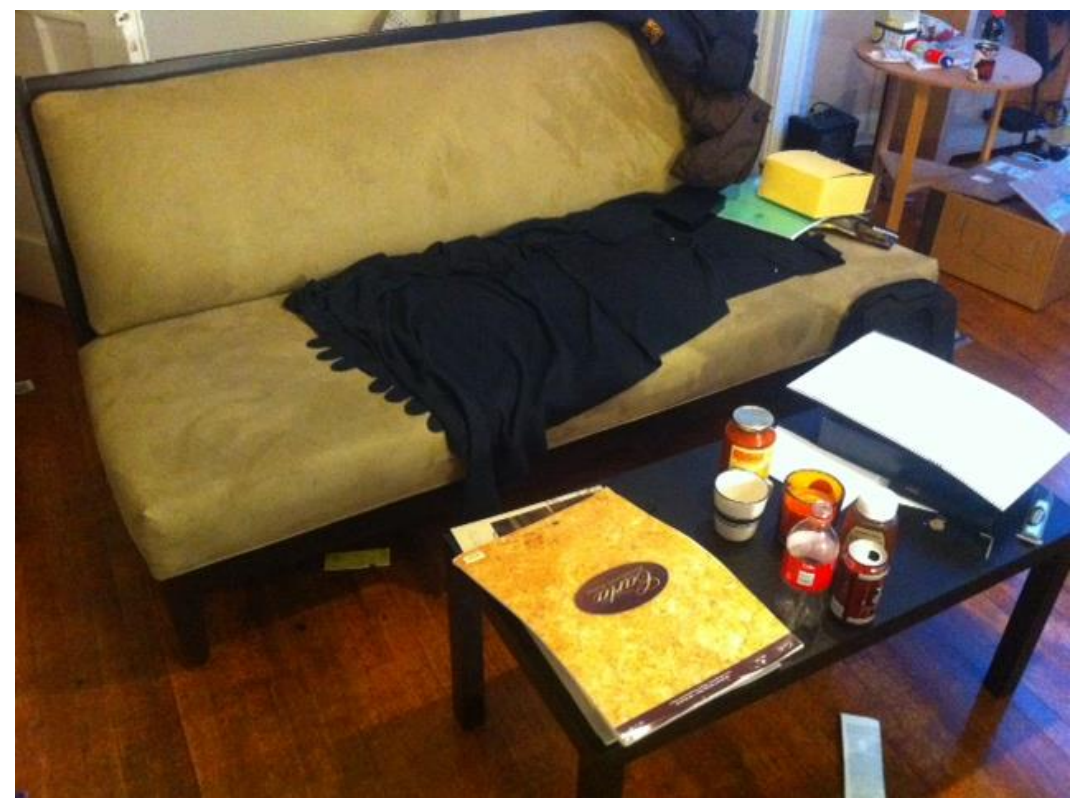

Figure 9. A couch, obviously a place for socializing.

Throughout all study spaces, electrical outlets were valued highly. Particular care must be taken to provide electrical access for open group areas because these spaces are prone to spontaneous 
rearrangement and students are frequently seated away from walls, where electrical outlets are most standardly located. One subject photographed an open lobby in a conservatory building, and identified it as a place for regular socializing (Figure 10), but pointed out the problems created by insufficient number of electrical outlets. Though the student's photo provides a good view of numerous students in a pleasant, open space, the viewpoint is significant because the student took the photo while studying, standing up, near a drinking fountain where an electrical outlet was located. The student quickly identified addition of electrical outlets as the chief way to improve the space:

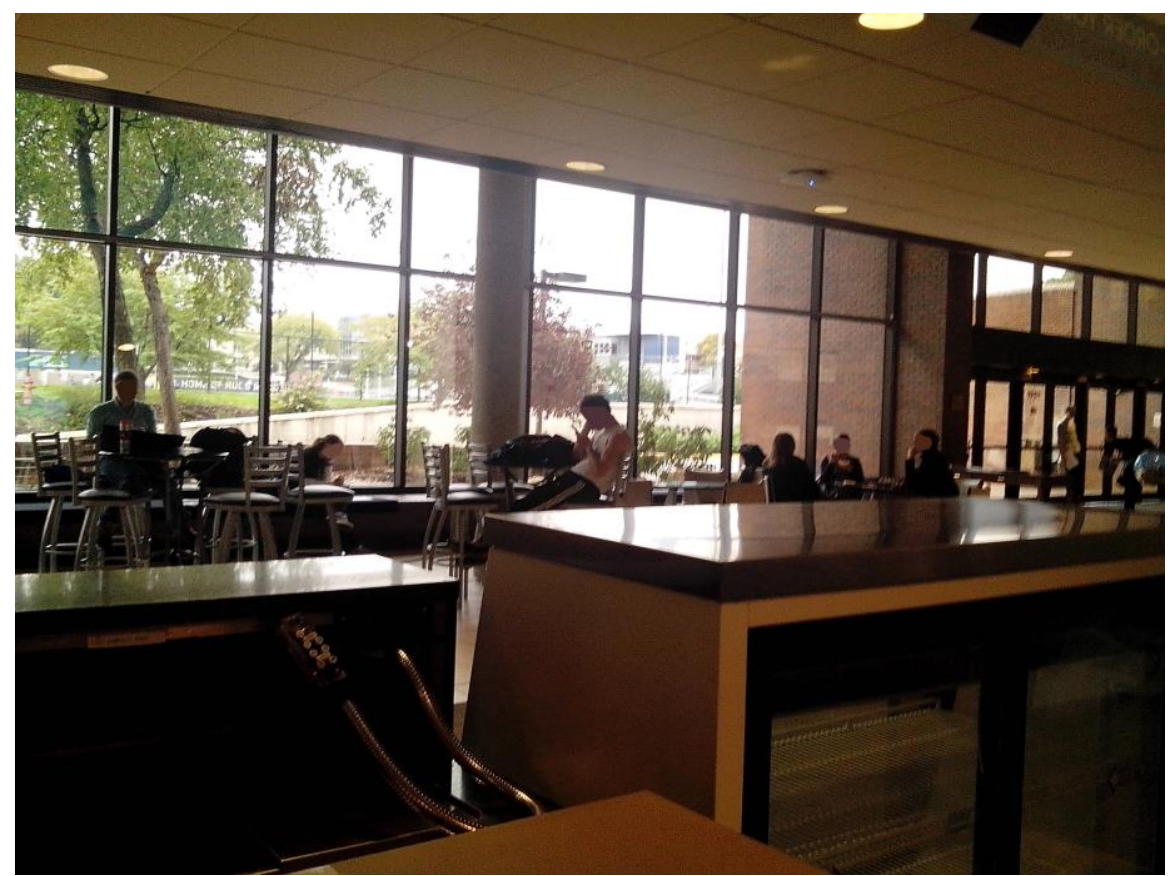

Figure 10. "A place where you socialize": an open lobby in a conservatory building.

Interviewer: Let's say that you could totally, kind of, reimagine this space, and make it even more awesome. For...both professional and sort of fun activities that you're doing. Is there anything that you would want in there?

Subject: More outlets. Especially over by the square of couches. [Not visible in the student's photo, Figure 10.] I mean, if they had, like, an outlet embedded into the floor or something, so that we wouldn't have- that one- all the way over there where you have to move the chair all the way back to the wall, that would be great. 'Cause, I mean, there are people all over the place who need to use their laptops, and what do you do when it gets down to one percent?

In summary, loud spaces support both individual and group study, as well as social activity which builds community. Furniture in loud spaces should accommodate both individuals and groups, and soft seating, especially couches, suggests an area is intended for social and group activity. Take particular care to provide bountiful electrical outlets throughout loud spaces. 
Soundproof space

Basic loud and quiet spaces are important but do not, alone, meet music and dance student needs, due to the aforementioned need to listen to music and heightened awareness of sound. A headphone use discussion opens exploration of music and dance student needs that necessitate a third type of study areas: "soundproof" space.

Headphone use is common among students in all disciplines, with the headphones used for nonstudy music listening. Students (again, in all disciplines) use headphones in both loud areas (to block out other noise) and in quiet areas (to create white noise without disturbing others.) Students in this study aligned with the general population in that some did, indeed use music to block noise or generally reduce distractions. However, their specific sensitivity to sound impacted the activity, particularly in that background music listening was usually differentiated from "study" music listening, and students who used music for background noise frequently chose music not in the style they primarily studied. For example, a classical musician preferred popular music in the background while writing or conducting research:

Subject: Especially when you're taking, like, theory classes and all you're doing is just sitting there and you're analyzing music. You need to- (sighs) I don't care if people don't think that it's great music. It makes me so happy...the other day in class we were talking about, "Do you listen to music when you study?" And I was like, "I can't listen to opera. I can't listen to any kind of classical music when I study because I end up listening to that. But, if I'm listening to like, Juicy J, just rapping about nonsense, I'm just like, 'Yes! I can write this paper now!"”

A composer expressed a similar sentiment, but noted there were times when background music in any genre - was not desired.

Subject: Most of [the] time, I listen to pop music. You know, because of the environment. You put your...earphones on...it's better to listen to pop music because classical music sometime[s], it is too soft, and it gets covered by the environment sound....

Interviewer: Do you listen to music while you're composing?

Subject: No....[But] sometime[s], yes. Like, when I write the sketch, I can listen to pop music, but when I do like orchestration- no....Because I need to hear.

In addition to individual listening, subjects frequently mentioned group listening and viewing activity, though study subjects did not currently do this work in the library. ${ }^{38}$ However, subjects clearly valued discovering new music and dance works as a group, and this activity fits naturally into library aims. One student's description of listening in a home area with small, but "decent" speakers (Figure 11) highlights the group aspect, while simultaneously emphasizing the serendipitous and community-building aspects: people listened because they were "around."

\footnotetext{
38 The UMKC music/media library does provide options for group listening and viewing: headphone splitters to accommodate two or three people at an individual listening/viewing station, and a single reservable group study room. Library staff do observe some students using these options. However, these options are not optimized in the ways that will be described in this subsection.
} 
Interviewer: And when you listen to music, do you listen by yourself, or with- just your roommates-?

Subject: It depends on who is in the house.... Sometimes, if my roommates [other music students] are home, we'll listen to music.... If it's just me, I'll listen to music.

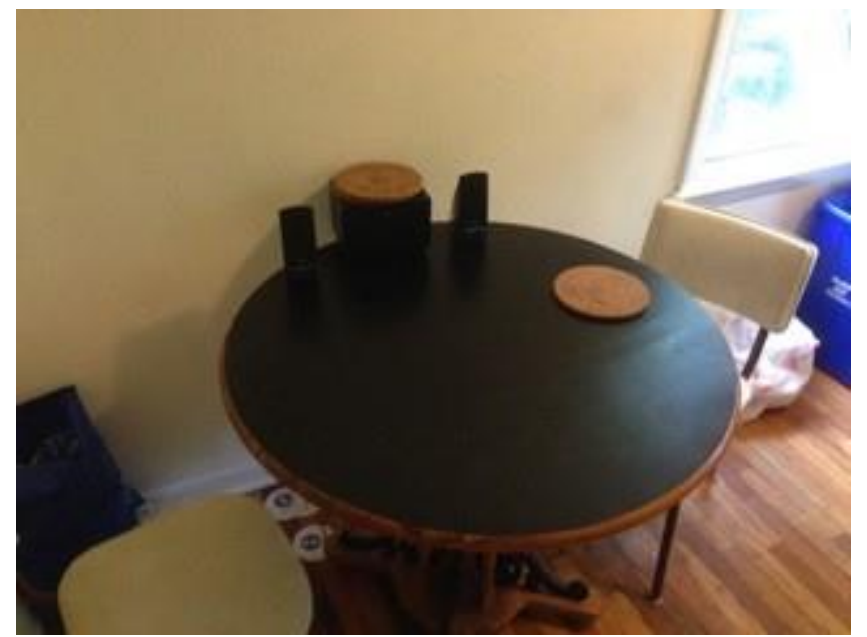

Figure 11. A table with small but "decent" speakers is "A great place to listen to music."

Students expressed interest in including listening spaces in the library. For example, when asked to describe a library or conservatory space that would facilitate experiences similar to browsing and listening via a friend's LP collection (previously shown as Figure 5), a student suggested:

Subject: I think it would be neat if there was just like- something like this [i.e. friend's LP collection]. Or maybe...it might be cool to have a list of everything.... I think that's a lot easier to be curious if you can touch and feel and look and see exactly what it is. And then you can do that rather than having- "Oh, okay. I need to go to the desk and ask for this record and then I can go listen to it." You know. So, that might be cool. Maybe it would be cool if there was a listening space with just comfy chairs and headphones or something like that. They could plug it in. And also, records aren't something that we get to see every day these days.

The student went on to explain how such a space could be used by groups as well as individuals. This would help grow an artistic community centered on music and dance works.

Interviewer: Is this something you can envision having groups of people doing?

Subject: Yeah...it'd be kind of cool...a couple times when my quintet was over- a couple friends were like, "Oh yeah. Go. Let's find something to listen to."

A dancer mentioned similar activities, but centered on dance videos rather than music recordings: 
Subject: Well, me and my best friend, we...go and she has videos of the Royal Ballet, or ABT [American Ballet Theatre] or PNB [Pacific Northwest Ballet] performing all different ballets that she's purchased, and so, I would say, almost every Saturday night, go over there, we'll eat a rotini or something and we'll basically just watch the ballet and critique it, and basically just be loud and obnoxious dancers.

The dancer explained how such a group viewing space might be used:

Interviewer: If there was a place in the library, the new library...that you could watch some of this, would it be like a home theatre setup,... Would it be a personal place, just for you to watch?

Subject: ...Both...I would say, a personal place that you could do it, or even, a room, with just a nice- you know, doesn't have be too big, even a 40" TV,... with some beanbags on the floor...I know we would utilize it, because it's easier than us all sitting on top of each other in the dorm room.

The challenges of creating soundproof space for communal listening space are clear in another student's explanation:

Interviewer: If there was a place on campus that had good speakers... available to youwhat space would they be in?

Subject: I don't really know, to be honest. I don't really know where it would be acceptable to just have loud noise playing. I mean, if there were a magical room in the library, or in the music building somewhere that uses space to just listen to music, that'd be pretty cool.

Interviewer: Like a sound-proof room or something?

Subject: Yeah....That would be excellent.

In creating soundproof spaces for groups, care must be taken to balance seclusion (which promotes focus) and openness (which promotes serendipity and artistic community.) Sometimes, seclusion is desired, but open, approachable spaces can facilitate informal, serendipitous encounters. Location, architectural design, and included amenities should all be considered. One student's photograph of "a place where you socialize" suggests possible characteristics of such an open, approachable group area (Figure 12). 


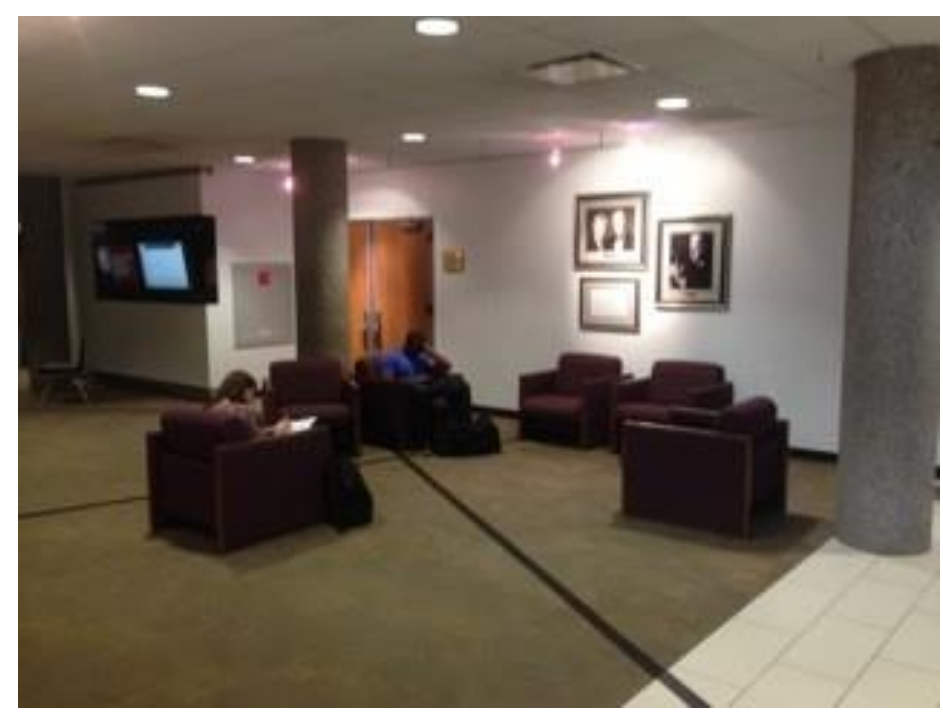

Figure 12. "A place where you socialize": gathering area near ensemble rehearsal room.

Subject: So, this is the main lobby at the PAC [Olson Performing Arts Center, a conservatory building including large instrumental ensemble rehearsal spaces].... This is where most of the people in the conservatory end up hanging out or something. Usually, before and after rehearsals since rehearsals are in the PAC behind the Recital Hall....

Interviewer: So you socialize here as well?

Subject: Yup, like after rehearsals and stuff, or before rehearsals I'll be there.

Interviewer: Do you meet up with your friends or do you meet any...students that happen to be there?

Subject: Usually, it's just whoever is there. But, you can be pretty certain that certain people will be there [by consulting the schedule of who is playing on which pieces.]...

Interviewer: What's that? Is a TV playing there? Or a giant sign, or something?

Subject: Yeah....[It] shows an event list of everything that's happening.... To be honest, I'm not really certain why but, sometimes it's useful because you'll see something and you're like, "I had no idea. You know, Berlin Philharmonic Quartet is going to be here. What?" So you can go and you'll see some concerts you're interested in or something.

This particular space promoted scholarly social activity for several reasons. It was located in a place students would naturally encounter, near a large ensemble rehearsal room. It included soft seating, already identified as a trigger for social space. It also included a screen which promoted passive discovery, in this case of upcoming concerts and recitals. A similar technological setup in a soundproof space could promote discovery of and interaction with music and dance works. The particular space in Figure 12 is clearly on the "open" end of the secluded-open spectrum, and might at times be more of a loud space than a group soundproof space. Nonetheless, its location within the overall facility (i.e. a space for gathering placed where gathering will 
naturally occur) and its inclusion of discovery aspects are important features to include in some group soundproof spaces.

\section{Variety of study spaces needed}

Students expressed needs that will be best met by an assortment of study spaces, including not only typical quiet and loud areas, but soundproof areas as well. All three space types should accommodate both individuals and groups and include ample electrical access. In group spaces, take particular care that electricity will be available even when furniture is moved around. Students will favor different spaces, depending on their study styles or the specific task at hand. These findings are related to Hursh and Avenarius's conclusion that students favored individual study carrels for long-term visits, but a multi-seat technology lab for shorter visits with more socializing. ${ }^{39}$ In the current study, students sometimes sought individual work areas where they could focus for extended times on particular tasks, but at other times they worked more casually and desired simultaneous social engagement. Therefore, features promoting social activity and community formation will be most successful in loud spaces and in open, group-optimized soundproof spaces.

Take care to locate study spaces appropriately within an overall facility. Quiet spaces should be in secluded areas. Place loud spaces in areas with more traffic. Balance soundproof spaces among high, medium, and low traffic areas, to create a variety of listening and viewing environments.

\section{Forces of habit}

This study's third major area of findings centered around the forces of habit and students' limited exploration of unknown places on campus, highlighting the importance of placing the library in a location students will naturally encounter. These findings are drawn from subject responses to the photo prompt "a place you feel lost." Initially, elicited photos appeared to contribute minimal information to this research. Only one student's photo, of the library exterior (representing the library as a whole), was along the lines of photos researchers hoped the prompt would elicit, i.e., an area which was a point of confusion related to students' (broadly defined) academic lives.

Subject: I feel lost in the library because there's like so much in here. You guys have, what, five floors or something like that, and I'm always having to ask where I need to go to find the place that I need to go.

This response was very broad, and other subject photos provided even less data to identify or illuminate relevant areas of confusion. Two students photographed musical notation for pieces they found challenging to play or listen to. Two other students photographed places not where they really felt lost or confused, but simply saw no need to use: a science lab and an oddly placed apartment balcony. The final student photographed surroundings while actually lost, driving around Kansas City.

Ultimately, however, the lack of campus spaces where students felt lost was revealing, particularly since four of the six subjects were incoming students who had been at the university

\footnotetext{
${ }^{39}$ Hursh and Avenarius, 104, 105.
} 
fewer than ten weeks at the time of the interview. As the student who photographed an apartment balcony explained:

Interviewer: This is a place you feel lost, right?

Subject: Actually, I don't have that kind of place.... But this like a place that I think, I have no idea why I need to come here....

Interviewer: So, you don't feel lost, but you don't know the purpose of that place. It doesn't serve a purpose?

Subject: Yeah....Most of [the] time, I don't feel lost, so I have no idea- I had to take the picture.

Though this particular subject was one of the two returning students, the response highlights the forces of routine and habit in behavior. Routines are formed quickly, and if the library is not in a physical location students will naturally encounter, students may not venture there much, even if the library includes numerous optimized study spaces, excellent browsing collections, and other valuable features. Locating the library in a space students will naturally encounter will help the library function as a community-building area where students discover, study, and create works of art both alone and with others.

\section{Library-related findings regarding practice rooms and classrooms}

This study's final group of findings highlights the research's holistic focus and the resulting collection of data about student lives beyond the library, particularly regarding student experiences and needs in two other campus spaces: practice rooms and classrooms. While a comprehensive examination of these areas is outside the scope of this paper, the library-related relevance will be highlighted here.

\section{Practice rooms}

Subjects discussed individual practice rooms, chamber rehearsal spaces, and dance studios, but rarely large ensemble rehearsal spaces. The lack of large ensemble discussion means simply that this study has little to say on such spaces, not that students do not value large ensembles. Both the study's restriction on photographing identifiable people and ensemble rehearsal's very nature would also have made photographing large ensemble rehearsals difficult. In fact, one student identified an ensemble rehearsal as "your favorite part of the day" and explained:

Subject: I like being there making music and playing and stuff. And our conductors... make it a good time. It's very charismatic and exciting.

In many ways, practicing and chamber rehearsals are activities similar to individual and group study in their requirement for focus, with the additional needs created because participants are both creating sound and highly sensitive to other sounds. Practice spaces, like study spaces, offer opportunities for creating artistic community. Well-equipped practice and rehearsal rooms in sufficient quantities encourage students to stay on campus, practice, and, when taking breaks from individual practice, to interact with others. Ideally, some practice and rehearsal spaces could be equipped with listening functionalities similar to those in individual and group 
soundproof study spaces, as well as recording features, facilitating easy transitions between making and listening to music. Furthermore, similar design requirements might make it feasible to have some overlap or dual use between practice rooms and individual soundproof study spaces, and between group soundproof study rooms and chamber rehearsal rooms.

\section{Classrooms}

Students spend a great deal of time in classroom spaces. Subjects in this study consistently expressed a preference for natural light in classrooms. In fact, three subjects (half of those interviewed) mentioned natural light as a positive characteristic of classroom space, and a fourth subject noted a preference for a well-lit dance studio over more dimly-lit dance studios. However, this preference should not be transported unquestioned into all library and study spaces, as evidenced by one student's explanation of a difference in lighting preference between an individual work space and a classroom (Figure 13).

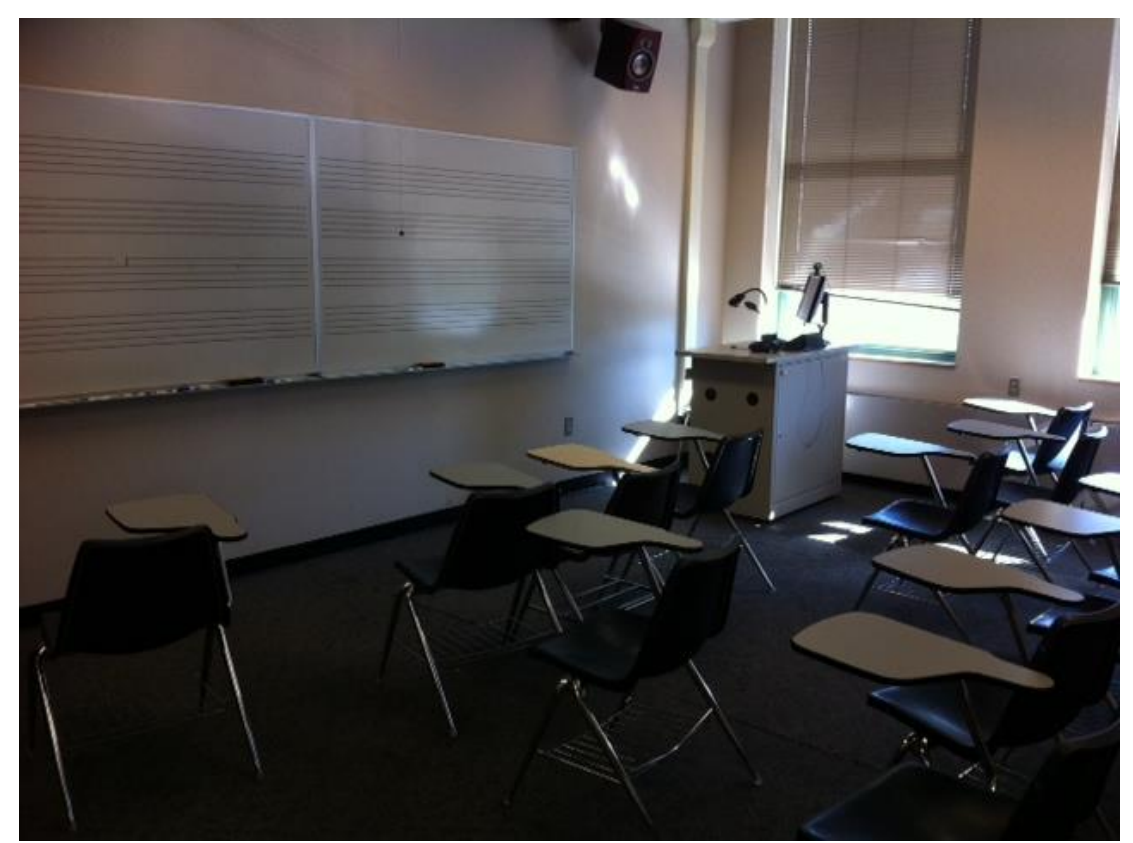

Figure 13. A student immediately identified the window as a feature of "A classroom you like."

Interviewer: [Is there anything] really good about the way this classroom is set up, that makes this class work well?

Student: No, but I like the window.

Interviewer: OK. I noticed in your room [where you live],... it looks like you don't have any windows.

Student: ...When I work, I prefer to work in the...dark, but [a] classroom should be brighter. Otherwise you can fall asleep. 
Therefore, the library should provide spaces both with and without natural light. The above student statement as well as other student statements regarding individual study spaces suggest that individual study rooms are one place where some students prefer a completely distractionfree environment, and find windows and natural light to be among those distractions. In contrast, natural light is valued in group areas, because students expect the focus to be less intense in group areas.

\section{Recommendations}

\section{Discovering and obtaining music and dance works}

Student choices of sources for discovering and obtaining music and dance works were influenced by six considerations. Availability was the most basic consideration, but because of frequently wide availability, most decisions were ultimately made based on the browsing experience, convenience, and cost. Quality and legal and ethical issues were much less influential. Librarians and teaching faculty should take a multi-pronged approach to this situation, simultaneously improving important functionality for highly valued considerations and educating students to make more informed, thoughtful choices.

First, the browsing experience and cost are obvious factors that can be emphasized to students to encourage them toward a basic start using library resources. The value students placed on a serendipitous browsing experience is particularly encouraging because learning and discovery are central to library goals. In addition, improvements to convenience of library resources are worthwhile but can be difficult to achieve and sustain because it is challenging to keep pace with ever-increasing convenience of other online sources.

Second, the real importance is not "using the library" but educating students to make informed choices based on source quality and legal and ethical issues, rather than defaulting to convenience and cost. Legal, ethical, and quality issues are areas where librarians and teaching faculty members can work to raise awareness and knowledge, equipping students to make informed decisions throughout their careers.

Finally, specific recommendations emanate from the value students placed on a serendipitous browsing experience. The value of a physically browsable notated music collection is strong support for providing open stacks browsing. If space is available, utilize stationary rather than compact shelving to support extended time in the stacks and place chairs and large tables nearby to support in-depth examination of materials removed from shelves.

This study found students were often confused about how library materials are organized, but students who did understand classification valued it highly, especially for notated music. In response, librarians installed physical signs within UMKC's notated music collection to identify major sections (Figure 14). This addition enhanced the patron browsing experience by making items easier to find, particularly in long shelves of narrow, pamphlet-bound notated music. Furthermore, it helped facilitate learning about and using call numbers. 


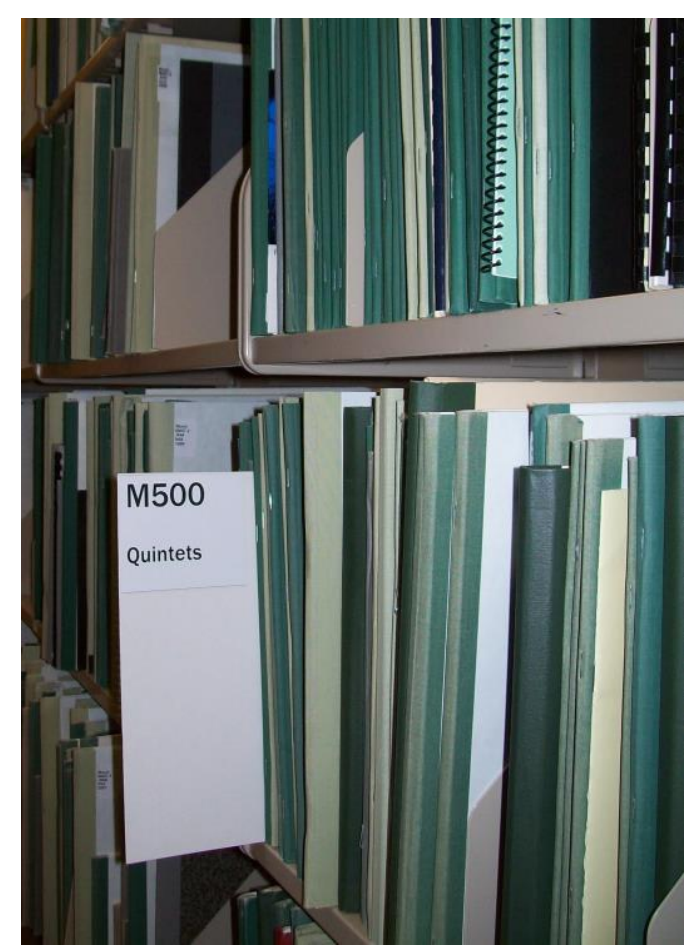

Figure 14. A sign filed within the physical notated music collection for way-finding and passive education regarding classification. (Photo courtesy of UMKC Libraries staff.)

Student preference for non-library sources for recordings stands in contrast to the situation for notated music. This difference is due to the excellent library browsing experience provided for notated music (primarily through physical stacks), in comparison to a problematic browsing experience for recordings. This preference serves as a call to increase functionality in online browsing and discovery options for recordings, whether these online options are OPACs, discovery tools, databases, or something else. Such improvements could also enhance the discovery experience for notated music by providing online options in addition to physical browsing. Libraries might also consider providing physical browsing experiences for recordings, though classification (particularly Library of Congress classification) can be problematic because many CDs contain works which fall into different class numbers.

\section{Study spaces and sound levels}

Music and dance student needs are not fully met by study spaces along the basic quiet-loud continuum. Instead, these students require three types of study spaces: quiet, loud, and soundproof. All study spaces should include configurations accommodating both individuals and groups as well as abundant, flexible access to electricity.

Quiet spaces benefit individuals who work best with minimal distractions. Some students prefer to be blocked off from surrounding activity as well as surrounding sound. Individual, semisecluded spaces are best for these students. Some students prefer a quiet area but gain energy from being around others similarly hard at work. Larger, possibly non-secluded, quiet areas are best for these students. Individual listening and viewing utilizing headphones (whether for study or background purposes) can be accommodated in spaces which are relatively, but not absolutely, quiet. 
Loud spaces accommodate group work, except focused listening and viewing, as well as individuals who work well in a more active environment containing white noise. Individual listening and viewing utilizing headphones (again, for both study and background purposes) can generally occur in loud spaces, though focused listening to Western Art Music may be difficult if the environmental volume level is too high. Loud areas, when approachable and correctly located, can also encourage serendipity and build a scholarly, artistic community where students naturally meet each other and works of art.

Soundproof spaces meet music and dance student needs to listen to and view music and dance audio and video in a focused manner. Individually-sized soundproof spaces facilitate listening to Western Art Music with all its dynamic variation, plus provide individual quiet study areas for those distracted by surrounding activity. Group soundproof areas are more challenging to create. Their primary purpose is group listening and viewing, and they can secondarily serve as general group study areas. In creating soundproof spaces for groups, care must be taken to balance seclusion (which promotes focus) and openness (which promotes serendipity and artistic community.) Ideally, provide multiple soundproof spaces for groups, with varying amounts of equipment, seclusion, and soundproofing. Some spaces should be open to facilitate informal, serendipitous encounters. Carefully placed and thoughtfully equipped gathering spaces are a strong opportunity for creating an artistic community. Strategically locate such spaces in natural gathering areas, and equip them with tools for serendipitous discovery, such as large screens or monitors and access to audio and video playback.

\section{Forces of habit}

Students, like humanity in general, establish habits in their campus activities and the locations they visit. If the library is not in a physical location students will naturally encounter, students may visit the library infrequently throughout their entire academic career. Locating the library in a space students will naturally encounter will facilitate the library's function as a communitybuilding area where students discover, study, and create works of art both alone and with others.

\section{Library-related findings regarding practice rooms and classrooms}

Practice rooms (including chamber rehearsal spaces) and classrooms were the non-library campus spaces most mentioned by study subjects. Practice rooms should be adequate in number and amenities, and might be equipped with listening and/or viewing equipment similar to the equipment placed in study spaces. Students placed a high value on natural light in classrooms. Similarly, natural light should be a feature of some library spaces and is most desirable in groupfocused areas.

\section{Conclusion}

Photo elicitation methods provide valuable information to plan and optimize spaces and services for music and dance students. This study highlights the value of ethnographic research with disciplinary student sub-populations. At UMKC, study findings have already been used to inform planning for a future Downtown Campus for the Arts and to guide improvements to current services and spaces for music and dance students. Additional ethnographic research (via photo elicitation or other methods) at UMKC and other institutions will further deepen knowledge of performing arts student behaviors, needs, and desires and facilitate refinement of the findings of 
this case study. In addition, this study's findings could be confirmed by future research utilizing less open-ended methods such as inferential statistical studies with a larger number of participants. In such future research, take care to collect data on students' year of study in addition to degree program and area of study.

Study researchers look forward to implementing study findings and expanding this research in the coming years. The photo elicitation method gave music and dance students a voice and provided data to confidently "picture" their needs and plan exciting, groundbreaking spaces in UMKC libraries and throughout the entire UMKC Conservatory of Music and Dance. 


\section{Works Cited}

Asher, Andrew and Susan Miller. So You Want to Do Anthropology in Your Library?: Or, A Practical Guide to Ethnographic Research in Libraries. ERAIL Project, 2011. http://www.erialproject.org/wp-content/uploads/2011/03/Toolkit-3.22.11.pdf

Briden, Judi. "Photo Surveys: Eliciting More Than You Knew to Ask For." In Studying Students: The Undergraduate Research Project at the University of Rochester, edited by Nancy Fried Foster and Susan Gibbons, 40-62. Chicago: Association of College and Research Libraries, 2007.

Briden, Judi and Sarada George. "Picture My Work." In Studying Students: A Second Look, edited by Nancy Fried Foster, 25-44. Chicago: Association of College and Research Libraries, 2013.

Delcore, Henry D., Mullooly, James, and Michael Scroggins with Kimberly Arnold, Elfego Franco, and Jada Gaspar. The Library Study at Fresno State. Fresno, CA: Institute of Public Anthropology, California State University, Fresno, 2009. http://www.fresnostate.edu/socialsciences/anthropology/ipa/thelibrarystudy.html

Dougan, Kirstin. "Finding the Right Notes: An Observational Study of Score and Recording Seeking Behaviors of Music Students." The Journal of Academic Librarianship 41 (2015): 61-67.

Duke, Lynda M. and Andrew D. Asher. College Libraries and Student Culture: What We Now Know. Chicago: ALA Editions, 2011.

Foster, Nancy Fried, ed. Studying Students: A Second Look. Chicago: Association of College and Research Libraries, 2013.

Foster, Nancy Fried and Susan Gibbons, eds. Studying Students: The Undergraduate Research Project at the University of Rochester. Chicago: Association of College and Research Libraries, 2007.

Gabridge, Tracy, Millicent Gaskell, and Amy Stout. "Information Seeking Through Students' Eyes: The MIT Photo Diary Study.” College \& Research Libraries 69, no. 6 (2008): $510-522$.

Hobbs, Kendall and Diane Klare. "User Driven Design: Using Ethnographic Techniques to Plan Student Study Space.” Technical Services Quarterly 27 (2010), 347-363.

Hursh, David W. and Christine B. Avenarius. "What Do Patrons Really Do in Music Libraries?: An Ethnographic Approach to Improving Library Services.” Music Reference Services Quarterly 16, no. 2 (2013): 84-108. 
International Federation of Library Associations and Institutions. Functional Requirements for Bibliographic Records. Final Report. As Amended and Corrected through February 2009. http://www.ifla.org/files/assets/cataloguing/frbr/frbr_2008.pdf.

Lin, Sao-Chen. "Perceptions of United States Academic Library Services of First-Year Graduate Students From Taiwan: A Photo-Elicitation Study." PhD diss., The University of Wisconsin-Madison, 2006.

Newcomer, Nara L. and David Hursh. "Calling All Academic Music Library Reference Desks: A Follow-Up Study.” Music Reference Services Quarterly 11, no. 2 (2008): 101-129.

Small, Mario Luis. “'How Many Cases Do I Need?': On Science and the Logic of Case Selection in Field-Based Research." Ethnography 10, no. 1 (2009): 5-38. 


\section{Appendix A: Interview Transcription Guidelines ${ }^{40}$}

\section{Change as little as possible.}

Accurately represent each speaker's words, conversational quality, and speech patterns.

However:

- Type contractions as spoken (I'll, not I will).

- Omit filler/ crutch words like "er," "um," "and then," "you know,"

- Omit interviewer comments like "how interesting" or "really?" or "wow!" which the interviewer made only to show that he/she was listening. Do include interviewer comments which were made to check/clarify understanding. If in doubt, include.

\section{Make it easy to read and understand.}

- Use correct (not phonetic) spelling of words, even if they have not been pronounced quite that way (but do not try to improve on the sentence structure and grammar).

- Use square brackets [ ] to enter any explanatory text (anything not in recording)

\section{Be complete.}

Transcribe all the words and transcribable sounds

- Including guttural sounds like ah, but with the exceptions noted in 1. above

- Use parentheses () with discretion to note audible expressions of emotion such as (laughs) when one speaker does, (laughter) when both do, or (pounds fist on table),

- You may also use parentheses to describe what is happening (reading from newspaper) or (sometimes) how words are spoken (with tears in his eyes). We do have the interview video, so it is not generally necessary to indicate/describe when interviewee is pointing to information on screen.

\section{Correlate transcript to recording}

- Approximately every 5 minutes, indicate the timing with brackets, i.e. [recording time: 5:00]

- Place the recording information on its own line, outside of the interview text. Don't break up the interview text to insert recording time.

- Whenever the photo changes, note the time as above, and the photo number.

\footnotetext{
40 The Utah Education Network's Interview Transcription Guidelines served as a starting point for this study's transcription guidelines. Utah Education Network, Interview Transcription Guidelines, http://www.uen.org/Lessonplan/downloadFile.cgi?file=22107-2-28569$\underline{\text { Interview_Transcription_Guidelines_handout_doc\&filename=Interview_Transcription_Guidelines_handout_doc }}$ (accessed November 24, 2015).
} 